\title{
Cognitive rehabilitation, self-management, psychotherapeutic and caregiver support interventions in progressive neurodegenerative conditions: a scoping review
}

Article

Accepted Version

Clare, L., Teale, J. C., Toms, G., Kudlicka, A., Evans, I., Abrahams, S., Goldstein, L. H., Hindle, J. V., Ho, A. K., Jahanshahi, M., Langdon, D., Morris, R., Snowden, J. S., Davies, R., Markova, I., Busse, M. and Thompson-Coon, J. (2019) Cognitive rehabilitation, self-management, psychotherapeutic and caregiver support interventions in progressive neurodegenerative conditions: a scoping review. Neurorehabilitation, 43 (4). pp. 443-471. ISSN 1053-8135 doi: https://doi.org/10.3233/NRE-172353 Available at https://centaur.reading.ac.uk/75895/

It is advisable to refer to the publisher's version if you intend to cite from the work. See Guidance on citing.

To link to this article DOI: http://dx.doi.org/10.3233/NRE-172353

Publisher: IOS 
All outputs in CentAUR are protected by Intellectual Property Rights law, including copyright law. Copyright and IPR is retained by the creators or other copyright holders. Terms and conditions for use of this material are defined in the End User Agreement.

\section{www.reading.ac.uk/centaur}

\section{CentAUR}

Central Archive at the University of Reading

Reading's research outputs online 


\section{Cognitive rehabilitation, self-management, psychotherapeutic and caregiver support}

interventions in progressive neurodegenerative conditions: a scoping review

Linda Clare ${ }^{1,2,3}$, Julia C. Teale ${ }^{1,2}$, Gill Toms ${ }^{4}$, Aleksandra Kudlicka ${ }^{1,2}$, Isobel Evans ${ }^{1}$, Sharon

Abrahams $^{5}$, Laura H. Goldstein ${ }^{6}$, John V. Hindle ${ }^{4}$, Aileen K. Ho ${ }^{7}$, Marjan Jahanshahi ${ }^{8}$, Dawn Langdon $^{9}$, Robin Morris ${ }^{6}$, Julie S. Snowden ${ }^{10}$, Rhys Davies ${ }^{11}$, Ivana Markova ${ }^{12}$, Monica Busse $^{13}$ and Jo Thompson-Coon ${ }^{2}$

1. Centre for Research in Ageing and Cognitive Health, University of Exeter

2. PenCLAHRC, University of Exeter Medical School

3. Centre for Research Excellence in Cognitive Health, Australian National University

4. School of Psychology, Bangor University

5. Psychology-PPLS, Euan MacDonald Centre for Motor Neurone Disease Research, The University of Edinburgh

6. King's College London, Institute of Psychiatry, Psychology and Neuroscience

7. School of Psychology and Clinical Language Sciences, University of Reading

8. Institute of Neurology, University College London

9. Royal Holloway University of London

10. University of Manchester

11. Walton Centre NHS Foundation Trust

12. University of Hull

13. Cardiff University

$\underline{\text { Corresponding author }}$

Professor Linda Clare, Centre for Research in Ageing and Cognitive Health (REACH), School of Psychology, University of Exeter, Perry Road, Exeter EX4 4QG, UK

$\underline{\text { 1.clare@exeter.ac.uk }}$

http://www.psychology.exeter.ac.uk/REACH 


\title{
Cognitive rehabilitation for people with progressive neurodegenerative conditions and cognitive disability: a scoping review
}

\begin{abstract}
BACKGROUND: Despite their potentially significant impact, cognitive disability may be overlooked in a number of progressive neurodegenerative conditions, as other difficulties dominate the clinical picture.

OBJECTIVE: We examined the extent, nature and range of the research evidence relating to cognitive rehabilitation, self-management, psychotherapeutic and caregiver support interventions in Parkinsonian disorders, multiple sclerosis (MS), frontotemporal dementias (FTD), motor neuron disease and Huntington's disease.
\end{abstract}

METHODS: Scoping review based on searches of MEDLINE and CINAHL up to 15 March 2016.

RESULTS: We included 140 eligible papers. Over half of the studies, and almost all the randomised controlled trials, related to MS, while a number of single case studies described interventions for people with FTD. CR interventions addressed functional ability, communication and interaction, behaviour or memory. The majority of psychotherapy interventions involved cognitive behavioural therapy for depression or anxiety. Selfmanagement interventions were mainly available for people with MS. There were few reports of interventions specific to caregivers. Numerous methodological challenges were identified. CONCLUSIONS: The limited range of studies for all conditions except MS suggests a need firstly to synthesise systematically the available evidence across conditions and secondly to develop well-designed studies to provide evidence about the effectiveness of CR and other psychological interventions.

Keywords: Parkinson's disease, multiple sclerosis, frontotemporal dementia, motor neuron disease, Huntington's disease, self-management, psychotherapy, caregiver 


\section{Introduction}

Progressive neurodegenerative conditions (PNCs), many age-related, affect over a million people in the UK alone and often result in cognitive disability. It is unrealistic to assume that there will be an early cure or means of prevention for all, or even most, progressive neurodegenerative conditions. Therefore, there is an urgent need for strategies that go beyond supportive care and enable people to function at the best level possible and to live well with cognitive disability resulting from neurodegenerative disease. Here we focus on five progressive neurodegenerative conditions in which cognitive disability, in some cases amounting to dementia, forms a significant part of the clinical picture. These are the Parkinsonian disorders (PDs) including Parkinson's disease (PD), progressive supranuclear palsy (PSP), multiple system atrophy (MSA), corticobasal degeneration (CBD) and dementia with Lewy Bodies (DLB), multiple sclerosis (MS), the frontotemporal dementias (FTDs) including behavioural variant FTD, semantic dementia (SD) and primary progressive aphasia (PPA), motor neuron disease (MND), and Huntington's disease (HD). We selected these five conditions, with a focus on the adult and older adult population, because they are amongst the commoner of the neurodegenerative diseases which apart from motor symptoms and behavioural changes are also characterised by significant albeit variable cognitive impairment. Alzheimer's disease is not covered here because of the already extensively-reviewed research (Bahar-Fuchs, Clare, \& Woods, 2013; Clare, 2008; Morris \& Becker, 2004).

Cognitive impairment is integral to FTDs and HD, and affects a significant proportion of people diagnosed with MND, PDs, and MS. Cognitive impairments progress in extent and severity over time, although the rate of progression is variable across conditions and across individuals affected, and does not always correspond with the staging of physical symptoms. In FTDs, HD, and most PDs, cognitive impairments progress to full dementia (Hindle, 
Petrelli, Clare, \& Kalbe, 2013), but this is rare in MS, and in MND occurs only where there is co-morbid FTD. Although the five conditions are very different in many respects, and have different pathogenic origins and affect different neural networks, there are common elements in terms of the underlying cognitive processes that are impaired. Table 1 summarises the cognitive domains affected and the behavioural and emotional features arising in each of the five conditions and demonstrates the extensive overlap in presentations.

$((($ Table 1)))

Impaired cognitive processes have wide-ranging effects. They may result in behavioural problems; for example, impaired executive function can involve poor judgement and decision-making, and can be associated with a loss of initiation and generation leading to apathy. Impaired cognition also contributes to the pathophysiology of motor symptoms; for example, problems with attention and conflict resolution contribute to mobility problems in PDs such as freezing of gait (Vandenbossche et al., 2011). Equally, motor symptoms may add to the cognitive challenges of daily life.

Cognitive changes, and the progression of cognitive impairment in some of these disorders, significantly affect important aspects of everyday life and well-being, including everyday functioning and behaviour (Birnboim \& Miller, 2004; Goretti, Portaccio, Zipoli, Razzolini, \& Amato, 2010; Goverover, Chiaravalloti, \& DeLuca, 2016; Goverover, Haas, \& DeLuca, 2016; Pirogovsky et al., 2014), employment (Benedict et al., 2016), communication and social interaction (Anderson, Simpson, Channon, Samuel, \& Brown, 2013; Cavallo et al., 2011; Eddy, Mahalingappa, \& Rickards, 2014; Meier, Charleston, \& Tippett, 2010; Merrilees, Klapper, Murphy, Lomen-Hoerth, \& Miller, 2010; Palmieri et al., 2010), 
involvement in decision-making (Abrahams, 2011; Martin et al., 2014; Meier et al., 2010; Merrilees et al., 2010), disease management (Bruce, Hancock, Arnett, \& Lynch, 2010), and emotional well-being and quality of life (Ho, Gilbert, Mason, Goodman, \& Barker, 2009; Ready, Mathews, Leserman, \& Paulsen, 2008; Schrag, Jahanshahi, \& Quinn, 2000; Shatil, Metzer, Horvitz, \& Miller, 2010). Cognitive changes have a major impact on the family members of those living with these conditions, and cognitive impairment is associated with caregiver burden and reduced caregiver quality of life (Labiano-Fontcuberta, Mitchell, Moreno-García, \& Benito-León, 2014; Morley et al., 2012; Ready et al., 2008), as are other psychiatric symptoms (Schrag, Hovris, Morley, Quinn, \& Jahanshahi, 2006). Some people may lack awareness of changes or difficulties, especially in FTD and HD, which can add considerably to caregiver burden. Depression is common among people with HD, MS and PDs (Burn, 2002; Siegert \& Abernethy, 2005; Slaughter, Martens, \& Slaughter, 2001), and anxiety is also frequent in MS (Korostil \& Feinstein, 2007), while people with FTDs and MND may also experience low mood (Blass \& Rabins, 2009; Goldstein, Atkins, \& Leigh, 2002).

Because of the predominance of other difficulties, such as progressive motor system dysfunction (PDs, HD, MS, and MND) or behaviour and personality change (FTD and HD), the impact of cognitive change in these conditions is often underestimated and underrecognised. Furthermore, with the exception of FTD, people living with these conditions who have cognitive impairments are often excluded from intervention studies (Goodwin \& Lan, 2014). Consequently, there is limited guidance available that can inform clinicians and those living with or affected by these conditions about effective non-pharmacological ways of managing the impact of cognitive impairment and supporting optimal functioning. Appropriate 
pharmacological treatment where indicated is of course essential, but here we focus on nonpharmacological approaches.

Importantly, strategies for managing the effects of cognitive impairment and optimising functioning are not condition-specific. The application of common strategies can be tailored to the specific needs of the population and the individual, for example by making adaptations to account for motor or sensory limitations. This means that evidence from a range of conditions could potentially be assembled to provide professionals with practical guidance that enables them to work flexibly across conditions, drawing on the commonalities that can be observed.

Rehabilitation is key to managing cognitive and behavioural disability and optimising functioning. Rehabilitation for people with cognitive disability, termed 'cognitive rehabilitation' (CR) and sometimes also referred to as 'reablement', focuses on enabling each individual to function at his/her optimal level given the nature and extent of cognitive impairment, and to remain engaged with an appropriate social context (Beaumont \& Morris, 2005). CR uses a goal-oriented approach to facilitate improved management of the consequences of functional disability, and has already been successfully applied to assist people with dementia due to Alzheimer's or vascular disease (Bahar-Fuchs et al., 2013; Clare et al., 2013; Clare et al., 2010). Key elements are an individualised formulation, collaborative identification of specific realistic and meaningful goals, application of evidence-based behavioural strategies, and adjustment of goals and strategies in response to changes in the person's condition. The rehabilitation therapist assesses the person's current ability and the demands of the activity the person wishes or needs to do, identifies where mismatches arise, and collaboratively develops a therapy plan to support goal attainment. While rehabilitation goals may be very different depending on condition, stage and degree of severity, the overall 
aims of supporting independence and self-determination, and the repertoire of behavioural methods and techniques employed to support goal attainment, are likely to be similar.

Cognitive rehabilitation is complemented by three other key related psychosocial intervention approaches:

- Access to psychological therapies to address mental health needs such as anxiety or depression, and support the process of adjustment to living with a neurodegenerative condition. This may be a vital precursor to enabling participation in cognitive rehabilitation interventions.

- Providing information about the condition and encouraging an appropriate degree of self-management. This encompasses support for decision-making and planning for future care needs, including end-of-life care where relevant, and may include facilitating opportunities for social contact and engagement in enjoyable and meaningful activities. Greater understanding of a condition can facilitate engagement with rehabilitation.

- Support for caregivers. Effective support for caregivers includes provision of information, advice, emotional support and skills training, enabling them to support the process of cognitive rehabilitation and to provide optimal care that promotes the functioning, independence and self-determination of the person with cognitive impairment.

While pharmacological interventions play a part in the management of cognitive and behavioural difficulties, and can facilitate participation in non-pharmacological interventions, the indications for and efficacy of such treatments represent a complex and specialised topic that is beyond the scope of the present review. Here we focus on non-pharmacological approaches. 
Drawing together the evidence for the efficacy of rehabilitation interventions, together with associated domains of self-management, psychotherapeutic and caregiver support interventions, across the five PNCs, could provide a basis for developing guidance for health and social care professionals, and information for patients and carers living with PNCs, and could identify gaps in knowledge to be addressed by further research. While reviews have examined the efficacy of specific interventions for one or more conditions (Croot, Nickels, Laurence, \& Manning, 2009; Fernie, Kollmann, \& Brown, 2015; Hindle et al., 2013; Langenbahn, Ashman, Cantor, \& Trott, 2013; Rae-Grant et al., 2011) no review has yet integrated the evidence for cognitive rehabilitation and associated intervention approaches across all five conditions. Here we outline a scoping review (Arksey \& O'Malley, 2005; Colquhoun et al., 2014; Levac, Colquhoun, \& O'Brien, 2010; Pham et al., 2014) undertaken to determine the feasibility of this approach and its potential for improving the quality of support available to people with these conditions and their caregivers. We defined our review question as: 'What is the extent, nature and range of the research evidence relating to the efficacy, experience and implementation of cognitive rehabilitation, self-management, psychotherapeutic and caregiver support interventions in PDs, MS, FTD, HD and MND?'

\section{Materials and methods}

In line with recommended scoping review methods, we aimed to map the application of key intervention concepts, and types of evidence available, in relation to people living with the conditions of interest and their caregivers by systematically searching, selecting and synthesising existing knowledge (Arksey \& O'Malley, 2005) and to consider the implications for practice, within the constraints imposed by budgets and time availability (Levac et al., 2010). We adopted a broad focus and considered a wide range of study designs in order to 
provide a descriptive overview of the available evidence (Pham et al., 2014). We consulted with people living with PNCs when formulating plans for the project.

We conducted searches in the MEDLINE and CINAHL databases on 15 and 23 January 2015, and updated searches on 15 March 2016, combining search terms designed to capture the relevant types of intervention and the conditions of interest. We selected these databases for pragmatic reasons, given time and budget constraints, as two of the largest and most widelyused sources likely to provide the most effective search results. Our target populations were people with one of the five PNCs or carers of people with one of the five PNCs. Target interventions were cognitive rehabilitation, psychological therapy or self-management, education or support interventions for people with one of the five PNCs, or education, skills training or support interventions for caregivers of people with one of the five PNCs. We considered any or no comparators, and any outcomes. Search terms covering populations and interventions are shown in table 2.

(((Table 2)))

Studies were included if a) participants had one of the five PNCs or were carers of people with one of these conditions; b) participants with PNCs who had cognitive impairment were included or not explicitly excluded; and c) the paper reported quantitative or qualitative data relating to a cognitive rehabilitation, psychological therapy or self-management, education or support intervention for people with one of the five PNCs, or an education, skills training or support intervention for caregivers of people with one of the five PNCs. For PDs and MS, searches were limited to the period from 2010 to the present due to the volume of records available for those conditions. Key studies known to the research team were also included. 
Title, abstract and full-text screening was carried out by GT, JCT, AK and IE. The screening process was managed in EndNote ${ }^{\circledR}$ Version 7. After merging search results from MEDLINE and CINAHL, duplicates were identified in Endnote first by using the default settings in 'Find duplicates' and then by adjusting the search criteria and inspecting reference lists ordered alphabetically by title and by author. At each stage of screening, each item was considered by at least two people working independently and any disagreements were discussed in order to reach a consensus. Where a lack of clarity remained, the item was referred to LC for a final decision. Eligible studies were grouped according to type as follows:

1. Cognitive rehabilitation interventions addressing cognitive or behavioural disability.

2. Psychological interventions addressing mood or adjustment to living with a neurodegenerative disorder.

3. Education, self-management and support interventions, including symptom management.

4. Education, skills training and support interventions for carers of people living with neurodegenerative disorder, such as carer support groups.

\section{Results}

Figure 1 provides a flowchart of the process of study identification and selection. Our searches yielded 19,187 unique records, of which 2,508 were retained for abstract screening and 731 were selected for full-text assessment. At this stage 154 papers were not readily obtainable and of the remaining 577 records, 140 reported relevant studies. Over half of the included studies focused on MS (74 studies, 53\% of total). FTD (27 studies) accounted for 19\%, PDs (19 studies) for $14 \%$, HD (10 studies) for $7 \%$ and MND (10 studies) for $7 \%$ of the total. The included studies for each PNC are summarised by research design and by topic in table 3 . 
$((($ Figure 1)))

(((Table 3)))

To prepare a descriptive overview, the identified studies were grouped into the four intervention categories: cognitive rehabilitation (63 studies), psychological therapies for adjustment and mood (28 studies), education and self-management (42 studies), and support for carers (7 studies). A descriptive summary of the included studies, grouped by category and condition, is provided in table 4. Following the review of each category, methodological issues and challenges are considered.

$((($ Table 4$)))$

\subsection{Cognitive rehabilitation}

The cognitive rehabilitation interventions described were conducted either with individuals, in groups, or as part of multi-component treatment programmes. Interventions focused on functional ability, communication and interaction, behaviour or memory. Examples of studies using this approach were found across all five conditions. Of the 21 studies found involving people with FTD and SD, most were single case designs. Sample sizes ranged from $1-9$. In contrast the 21 studies in MS (Gentry, 2008; Lincoln, Dent, \& Harding, 2003; Lincoln et al., 2002) included 8 randomised controlled trials and sample sizes ranged from $1-240$. There were 7 studies in HD (Mattern \& Kane, 2007), of which 5 evaluated the effects of inpatient multidisciplinary team interventions and 2 were single case designs. There were 9 studies of PDs (Jain, Dawson, Quinn, \& Playford, 2004), including one pilot RCT and one multi-centre RCT. For MND, there were 4 case studies (Kaiser et al., 2001) and one between groups 
retrospective analysis including 344 people (Traynor, Alexander, Corr, Frost, \& Hardiman, 2003).

Individualised, goal-oriented interventions to support everyday functioning, activities of daily living and self-care draw on compensatory methods such as the use of memory aids, restorative methods including techniques to help take in and recall information, such as spaced retrieval, and environmental adaptations (Buchanan, Christenson, Houlihan, \& Ostrom, 2011). Studies examining the relative benefits of different techniques provide information about which strategies are most helpful for whom in which contexts (Goverover, Chiaravalloti, \& DeLuca, 2008). Drawing on evidence about the efficacy of specific techniques and approaches, individual interventions are designed to address specific goals or needs, taking account of the individual's profile of strengths and limitations in cognitive and functional ability. Examples of studies using this approach were found across all five conditions.

Individualised, goal-oriented interventions to support communication and social interaction include the introduction of specific information processing strategies as well as the use of assistive communication aids and compensatory strategies and development of non-verbal communication skills (Croot et al., 2009; Kortte \& Rogalski, 2013). Use of communication aids to enhance interaction was described for people with HD (Klasner \& Yorkston, 2001). Extensive research in the FTDs applied a range of techniques to support relearning or maintenance of semantic knowledge (Bier et al., 2009; Dewar, Patterson, Wilson, \& Graham, 2009; Dressel et al., 2010; Jokel \& Anderson, 2012; Jokel, Rochon, \& Leonard, 2006; Newhart et al., 2009; Robinson, Druks, Hodges, \& Garrard, 2009; Savage, Ballard, Piguet, \& Hodges, 2013; Savage, Piguet, \& Hodges, 2015; Snowden, Kindell, Thompson, Richardson, \& Neary, 2012; Snowden \& Neary, 2002; Suárez-González et al., 2015). Some studies considered 
maintenance of gains and transfer to everyday life (Bier et al., 2009; Robinson et al., 2009; Savage et al., 2013).

Individualised, goal-oriented interventions for behaviour are based on an individual formulation and on an understanding of the antecedents, consequences and functions of the given behaviour, and can help to reduce the impact of behavioural changes and hence support everyday functioning, relationships and social interactions. Techniques include introducing distraction and controlling triggers, as well as implementing environmental modifications, aids and adaptations (Croot et al., 2009). The use of this approach was reported for people with FTD and MND (Cleary, 2008; Fick, van der Borgh, Jansen, \& Koopmans, 2014).

Cognitive rehabilitation interventions for memory and other cognitive difficulties were reported mainly in MS, often using a group format. These interventions, for people with mild to moderate impairments in memory, attention or executive function, encourage the use of compensatory and restorative strategies, environmental adaptations, and assistive technology. Included studies targeted self-efficacy and strategy use (Shevil \& Finlayson, 2009, 2010; Stuifbergen et al., 2012) and subjective memory problems (Carr, das Nair, Schwartz, \& Lincoln, 2014).

Cognitive rehabilitation forms a component of some multi-disciplinary rehabilitation programmes. Rehabilitation programmes conducted on an in-patient or out-patient basis may include a focus on addressing the consequences of cognitive impairments, although it is often not possible to determine the extent to which this contributes to the overall outcomes. Such programmes have been reported for example in HD, aiming to reduce disability and improve 
participation and quality of life (Frich, Røthing, \& Berge, 2014; Piira et al., 2013; Thompson et al., 2013; Zinzi et al., 2007).

\subsection{Psychological interventions for adjustment and mood}

The majority of studies were found in MS; of 17 included studies, 7 were RCTs. Fourteen studies evaluated the effects of cognitive behavioural therapy (Mohr et al., 2005) and 2 focused on acceptance and commitment therapy (Nordin \& Rorsman, 2012). The majority of these were individual interventions, although there were also some group-based interventions addressing anxiety and depression, using approaches such as CBT, mindfulness, or acceptance and commitment therapy. There were 5 studies in PDs, including one RCT; all evaluated CBT interventions (Dobkin, Allen, \& Menza, 2007; Dobkin et al., 2011; Dobkin et al., 2014) and all but one of these were delivered on a one-to-one basis. Three studies in MND included an RCT of individual psychotherapy (Averill, Kasarskis, \& Segerstrom, 2013), a feasibility study of dignity therapy (Bentley, O'Connor, Kane, \& Breen, 2014), and a case study of a CBT-based intervention (Pérez \& Dapueto, 2014). Two case studies in HD reported a CBT (Silver, 2003) and a remotivation therapy (Sullivan, Bird, Alpay, \& Cha, 2001) intervention respectively. Thus while CBT has been used to address mood and emotions in a range of PNCs (Fernie et al., 2015), other psychotherapeutic approaches, such as dignity therapy and remotivation therapy, have also been reported, although overall the evidence-base appears limited (Gould et al., 2015). There were no reports of psychotherapeutic interventions for people with FTD.

\subsection{Education and self-management}

There were 36 studies in MS reporting education, self-management and support groups conducted either in person, via telephone or online, including 15 RCTs and a number of 
qualitative evaluations (Cecil, 2014; Regan et al., 2008). Four studies reported similar interventions for people with PD (Mulligan, Arps, Bancroft, Mountfort, \& Polkinghorne, 2011) and one study surveyed 726 people about their experiences of using support groups (Dorsey et al., 2010). Two studies sought the views of people with MND attending a support group (Kasarkis, Elza, Bishop, \& Spears, 1997; Regan et al., 2008). These surveys suggest that support groups may be accessed by significant numbers of people with some PNCs, but that outcomes are rarely evaluated. There were no reports of education, self-management or support groups for people with HD or FTD.

\subsection{Support for caregivers}

Only a small number of studies examined the effects of interventions for caregivers of people with PNCs. These carer interventions covered a mixture of progressive neurodegenerative disorders: FTD, HD, PDs and atypical early-onset dementias (Mioshi, McKinnon, Savage, O’Connor, \& Hodges, 2013). Five studies reported on the effects of participating in caregiver support groups. One study investigated whether participants were in contact outside of group meetings (Dipple \& Evans, 1998). One study assessed the effects of a positive emotion skillbuilding intervention (Dowling et al., 2014).

\subsection{Methodological issues}

Relevant studies were identified across all five conditions and all four types of intervention. However, the distribution across conditions and types of intervention was highly skewed with almost half of all studies, and $89 \%$ of all RCTs, relating to MS. There was a lack of randomised controlled trials in relation to the rarer PNCs. In many cases participant characteristics were insufficiently detailed; descriptions of the type and degree of cognitive impairment were often limited or even lacking altogether. Interventions implemented in group studies and RCTs were 
often poorly-described, although in contrast the availability of numerous single-case designs meant that some interventions were clearly characterised. Interventions were also sometimes wrongly labelled with misleading names which did not properly reflect the nature of the intervention being reported. Reporting of case studies tended to focus on specific changes in performance relating to goals, needs or behaviours directly targeted in the intervention. In contrast, larger trials often reported only more distal measures such as quality of life or mood, covering areas where there may not necessarily be problems or impairments at baseline, or focused on measures of impairment such as neuropsychological tests which would not necessarily be expected to improve.

\section{Discussion}

This scoping review shows that there is a body of evidence across the five PNCs, despite the relative rarity of conditions such as FTD, HD and MND (Bilney, Morris, \& Perry, 2003; Langenbahn et al., 2013), the lack of emphasis on cognitive and behavioural disability relative to other aspects of the condition in PD, MS and MND (Hindle et al., 2013), and the frequent exclusion from trials of participants with any degree of cognitive impairment or psychiatric comorbidity. The review yielded relevant studies across all five conditions and all four types of intervention. However, the distribution across conditions and types of intervention was highly skewed with a large proportion of studies relating to MS, where the depth and quality includes Class 1 evidence (Chiaravalloti, Moore, Nikelshpur, \& DeLuca, 2013). The evidence for cognitive rehabilitation in MS was examined in a previously-published Cochrane review (Rosti-Otajärvi \& Hämäläinen, 2014). Thus, the need for further research is likely to be greater for the other four conditions. 
The limited number of studies in PDs was somewhat surprising, given that PD itself is the most frequently-occurring PNC after Alzheimer's disease, cognitive impairment is widespread, and a high proportion of people living with PD will eventually develop dementia. This may have resulted in part from the time constraints that were imposed on the search period due to the very large numbers of records identified, but is likely also to reflect the lesser emphasis placed on cognitive as opposed to motor symptoms in PDs. The nature of FTD, HD and MND make it difficult to gather large enough sample sizes for single-centre intervention trials, so it is to be expected that the majority of reports would focus on single-case designs. For these rare conditions, multi-centre studies will be required to demonstrate effectiveness of interventions at group level.

With regard to types of intervention, the largest group of studies reported cognitive rehabilitation interventions. There were relatively few studies of psychological interventions or of self-management, education or support. The progressive nature of the cognitive and behavioural changes in FTD and HD, as well as debilitating motor aspects in HD, may limit the perceived relevance of these approaches, while people with PDs who develop significant cognitive impairment are likely to have been living with the condition for some time. Additionally, however, many professionals and services providing psychological interventions will not have a specific remit to provide services to these groups, and may lack knowledge about these disorders and experience difficulty in adapting the interventions to take account of motor problems and other condition-specific constraints. There is a need to develop a clear understanding about which interventions are most appropriate for people with each condition and how these may best be adapted to ensure suitability and acceptability. There were surprisingly few studies of support for caregivers of people with these conditions; possibly some caregivers are accessing support from charities focused on the specific conditions while 
others may be accessing generic support for caregivers of people with dementia or a range of disabilities, but these approaches are not being evaluated systematically.

The findings highlight some of the key challenges inherent in attempting to synthesise evidence regarding psychosocial interventions, which must be addressed in order to provide definitive conclusions about efficacy and useful information for practitioners. These relate to study design, selection of participants, description of interventions, application of specific rehabilitation techniques, and choice of outcome measures. The lack of randomised controlled trials in relation to the rarer PNCs limits confidence in the robustness and generalisability of findings, especially as all the included studies reported some positive results, raising concerns about possible publication bias. Participants with PNCs are heterogeneous, and it is important to characterise the type and degree of cognitive impairment, and to take participant characteristics into account in order to provide information that is useful to practitioners. Similarly, clear descriptions of interventions are needed. It is important that interventions are correctly named and clearly described. Specific cognitive rehabilitation techniques and strategies could be applied in different ways across studies, making it especially important to derive appropriate guidance on how to incorporate these strategies into practice. In larger trials where evaluation focused on areas where participants might not have impairments or specific needs at baseline, or on measures of impairment which would not necessarily be expected to improve, the trial design could yield a negative outcome for a potentially-effective intervention. It is important to acknowledge that in a progressive condition an outcome of no change or slowed deterioration can indicate treatment effectiveness (Croot et al., 2009).

This review has a number of limitations. In undertaking the review, pragmatic considerations regarding budget and time available had to be balanced against achieving sufficient coverage 
and breadth (Levac et al., 2010). More comprehensive searches and the ability to access papers that were not readily available would yield additional studies for inclusion; however, while we may not have accessed the full extent of the evidence, we believe that the scoping searches have provided a reasonably comprehensive picture of the nature and range of the evidence available. We have not undertaken any formal assessment of the quality of individual studies, but this is in line with the procedures adopted in other scoping reviews (Pham et al., 2014), where the aim is to gain an overview of the evidence rather than to make a detailed assessment of individual studies. We considered that given the preliminary nature of this review, an evaluation of study quality would not have added significantly to the work.

\section{Conclusions}

This scoping review has described the extent, nature and range of the research evidence relating to the effectiveness, experience and implementation of cognitive rehabilitation, selfmanagement, psychotherapeutic and caregiver support interventions in PDs, MS, FTD, HD and MND. The limited range of studies for all conditions except MS suggests it will be important firstly to systematically synthesise the available evidence across these conditions, taking account of the methodological challenges inherent in this endeavour, and secondly to build on this by developing rigorous, well-designed studies to provide robust evidence about the effectiveness of CR and other psychological interventions in PDs, FTD, HD and MND. There is a need for evidence that can provide a basis for developing guidance to support the practice of health and social care professionals, and advice for people affected by these conditions and their carers, that could enhance the possibility of living well with cognitive disability. 


\section{Declaration of interest statement}

DL reports: consultancy from Novartis, Bayer, TEVA, Biogen, Merck; speaker bureau for Almirall, TEVA, Biogen, Novartis, Bayer, Excemed; research grants from Novartis, Biogen, Bayer. All monies are paid to DL's university.

All other authors report no conflicts of interest.

\section{Acknowledgements}

AK acknowledges support from the National Institute for Health Research (NIHR) Health Technology Assessment (HTA) programme; PI Professor L Clare; HTA reference 11/15/04. LHG acknowledges that this paper represents independent research part-funded by the National Institute for Health Research (NIHR) Dementia Biomedical Research Unit at South London and Maudsley NHS Foundation Trust and King's College London; the views expressed are those of the author and not necessarily those of the NHS, the NIHR or the Department of Health. 


\section{References}

A'Campo, L., Spliethoff-Kamminga, N., Macht, M., Roos, R., \& Consortium, E. (2010). Caregiver education in Parkinson's disease: formative evaluation of a standardized program in seven European countries. Quality of Life Research, 19(1), 55-64. doi:10.1007/s11136-009-9559-y

A'Campo, L., Spliethoff-Kamminga, N., \& Roos, R. (2011). An evaluation of the patient education programme for Parkinson's disease in clinical practice. International Journal of Clinical Practice, 65(11), 11731179. doi:10.1111/j.1742-1241.2011.02765.x

Abrahams, S. (2011). Social cognition in amyotrophic lateral sclerosis. Neurodegenerative Disease Management, 1(5), 397-405. doi:10.2217/nmt.11.54

Allen, D. N., Goldstein, G., Heyman, R. A., \& Rondinelli, T. (1998). Teaching memory strategies to persons with multiple sclerosis. Journal of Rehabilitation Research and Development, 35(4), 405-410.

Allen, D. N., Longmore, S., \& Goldstein, G. (1995). Memory training and multiple sclerosis: a case study. International Journal of Rehabilitation and Health, 1(3), 189-202.

Anderson, R. J., Simpson, A. C., Channon, S., Samuel, M., \& Brown, R. G. (2013). Social problem solving, social cognition, and mild cognitive impairment in Parkinson's disease. Behavioral Neuroscience, 127(2), 184. doi: $10.1037 / \mathrm{a} 0030250$

Arksey, H., \& O'Malley, L. (2005). Scoping studies: towards a methodological framework. International Journal of Social Research Methodology, 8(1), 19-32.

Asano, M., Preissner, K., Duffy, R., Meixell, M., \& Finlayson, M. (2015). Goals set after completing a teleconference-delivered program for managing multiple sclerosis fatigue. American Journal of Occupational Therapy, 69(3), 6903290010p6903290011-6903290010p6903290018. doi:10.5014/ajot.2015.015370

Askey-Jones, S., David, A. S., Silber, E., Shaw, P., \& Chalder, T. (2013). Cognitive behaviour therapy for common mental disorders in people with Multiple Sclerosis: A bench marking study. Behaviour Research and Therapy, 51(10), 648-655. doi:10.1016/j.brat.2013.04.001

Averill, A. J., Kasarskis, E. J., \& Segerstrom, S. C. (2013). Expressive disclosure to improve well-being in patients with amyotrophic lateral sclerosis: a randomised, controlled trial. Psychology and Health, 28(6), 701713. doi:10.1080/08870446.2012.754891

Bahar-Fuchs, A., Clare, L., \& Woods, B. (2013). Cognitive training and cognitive rehabilitation for mild to moderate Alzheimer's disease and vascular dementia. Cochrane Database of Systematic Reviews, 6. doi:10.1002/14651858.CD003260

Barlow, J., Edwards, R., \& Turner, A. (2009). The experience of attending a lay-led, chronic disease selfmanagement programme from the perspective of participants with multiple sclerosis. Psychology and Health, 24(10), 1167-1180. doi:10.1080/08870440802040277

Barlow, J., Turner, A., Edwards, R., \& Gilchrist, M. (2009). A randomised controlled trial of lay-led selfmanagement for people with multiple sclerosis. Patient Education and Counseling, 77(1), 81-89. doi:10.1016/j.pec.2009.02.009

Beaumont, D. M., \& Morris, J. (2005). Rehabilitation in the NHS and social care. London: British Geriatrics Society.

Beckner, V., Howard, I., Vella, L., \& Mohr, D. C. (2010). Telephone-administered psychotherapy for depression in MS patients: moderating role of social support. Journal of Behavioral Medicine, 33(1), 47-59. doi:10.1007/s10865-009-9235-2

Benedict, R. H., Drake, A. S., Irwin, L. N., Frndak, S. E., Kunker, K. A., Khan, A. L., . . Weinstock-Guttman, B. (2016). Benchmarks of meaningful impairment on the MSFC and BICAMS. Multiple Sclerosis Journal, 1352458516633517.

Bentley, B., O'Connor, M., Kane, R., \& Breen, L. J. (2014). Feasibility, acceptability, and potential effectiveness of dignity therapy for people with motor neurone disease. PLoS One, 9(5), e96888. doi:10.1371/journal.pone.0096888

Bier, N., Brambati, S., Macoir, J., Paquette, G., Schmitz, X., Belleville, S., . . Joubert, S. (2015). Relying on procedural memory to enhance independence in daily living activities: smartphone use in a case of semantic dementia. Neuropsychological Rehabilitation, 25(6), 913-935. doi:10.1080/09602011.2014.997745

Bier, N., Macoir, J., Gagnon, L., Van der Linden, M., Louveaux, S., \& Desrosiers, J. (2009). Known, lost, and recovered: efficacy of formal-semantic therapy and spaced retrieval method in a case of semantic dementia. Aphasiology, 23(2), 210-235. doi:10.1080/00207590801942906

Bier, N., Macoir, J., Joubert, S., Bottari, C., Chayer, C., Pigot, H., \& Giroux, S. (2011). Cooking "shrimp à la créole": a pilot study of an ecological rehabilitation in semantic dementia. Neuropsychological Rehabilitation, 21(4), 455-483. doi:10.1080/09602011.2011.580614 
Bier, N., Paquette, G., \& Macoir, J. (2015). Smartphone for smart living: using new technologies to cope with everyday limitations in semantic dementia. Neuropsychological Rehabilitation, 1-21. doi:10.1080/09602011.2015.1094395

Bilney, B., Morris, M. E., \& Perry, A. (2003). Effectiveness of physiotherapy, occupational therapy, and speech pathology for people with Huntington's disease: a systematic review. Neurorehabilitation and Neural Repair, 17(1), 12-24. doi:10.1177/0888439002250448

Birnboim, S., \& Miller, A. (2004). Cognitive rehabilitation for multiple sclerosis patients with executive dysfunction. Journal of Cognitive Rehabilitation, 22(4), 11-18.

Blass, D. M., \& Rabins, P. V. (2009). Depression in frontotemporal dementia. Psychosomatics, 50(3), 239-247. doi:10.1176/appi.psy.50.3.239

Boeschoten, R. E., Nieuwenhuis, M. M., van Oppen, P., Uitdehaag, B. M. J., Polman, C. H., Collette, E. H., . . . Dekker, J. (2012). Feasibility and outcome of a web-based self-help intervention for depressive symptoms in patients with multiple sclerosis: a pilot study. Journal of the Neurological Sciences, 315(12), 104-109. doi:10.1016/j.jns.2011.11.016

Bombardier, C. H., Cunniffe, M., Wadhwani, R., Gibbons, L. E., Blake, K. D., \& Kraft, G. H. (2008). The efficacy of telephone counseling for health promotion in people with multiple sclerosis: a randomized controlled trial. Archives of Physical Medicine and Rehabilitation, 89(10), 1849-1856. doi:10.1016/j.apmr.2008.03.021

Bombardier, C. H., Ehde, D. M., Gibbons, L. E., Wadhwani, R., Sullivan, M. D., Rosenberg, D. E., \& Kraft, G. H. (2013). Telephone-based physical activity counseling for major depression in people with multiple sclerosis. Journal of Consulting and Clinical Psychology, 81(1), 89-99. doi:10.1037/a0031242

Bruce, J. M., Hancock, L. M., Arnett, P., \& Lynch, S. (2010). Treatment adherence in multiple sclerosis: association with emotional status, personality, and cognition. Journal of Behavioral Medicine, 33(3), 219-227.

Buchanan, J. A., Christenson, A., Houlihan, D., \& Ostrom, C. (2011). The role of behavior analysis in the rehabilitation of persons with dementia. Behavior Therapy, 42(1), 9-21. doi:10.1016/j.beth.2010.01.003

Burn, D. J. (2002). Depression in Parkinson's disease. European Journal of Neurology, 9(s3), 44-54. doi:10.1046/j.1468-1331.9.s3.6.x

Burns, M. N., Siddique, J., Fokuo, J. K., \& Mohr, D. C. (2010). Comorbid anxiety disorders and treatment of depression in people with multiple sclerosis. Rehabilitation Psychology, 55(3), 255-262. doi:10.1037/a0020492

Carr, S. E., das Nair, R., Schwartz, A. F., \& Lincoln, N. B. (2014). Group memory rehabilitation for people with multiple sclerosis: a feasibility randomized controlled trial. Clinical Rehabilitation, 28(6), 552-561. doi:10.1177/0269215513512336

Cavallo, M., Adenzato, M., MacPherson, S. E., Karwig, G., Enrici, I., \& Abrahams, S. (2011). Evidence of social understanding impairment in patients with amyotrophic lateral sclerosis. PLoS One, 6(10), e25948. doi:10.1371/journal.pone.0025948

Cecil, A. H. (2014). An 8-year telephone support group for home-bound people with multiple sclerosis: adapting therapeutic methods to overcome isolation and immobility. Social Work with Groups, 37(2), 129-141. doi:10.1080/01609513.2013.824371

Chiaravalloti, N. D., Moore, N. B., Nikelshpur, O. M., \& DeLuca, J. (2013). An RCT to treat learning impairment in multiple sclerosis: the MEMREHAB trial. Neurology, 81(24), 2066-2072.

Chiaravalloti, N. D., Wylie, G., Leavitt, V., \& Deluca, J. (2012). Increased cerebral activation after behavioral treatment for memory deficits in MS. Journal of Neurology, 259(7), 1337-1346. doi:10.1007/s00415011-6353-X

Ciancarelli, I., Tozzi, C. M., \& Carolei, A. (2013). Effectiveness of intensive neurorehabilitation in patients with Huntington's disease. European Journal of Physical and Rehabilitation Medicine, 49(2), 189-195.

Clancy, M., Drerup, M., \& Sullivan, A. B. (2015). Outcomes of cognitive-behavioral treatment for insomnia on insomnia, depression, and fatigue for individuals with multiple sclerosis. International Journal of MS Care, 17(6), 261-267. doi:10.7224/1537-2073.2014-071

Clare, L. (2008). Neuropsychological Rehabilitation and People with Dementia. Hove and New York: Psychology Press.

Clare, L., Bayer, A., Burns, A., Corbett, A., Jones, R., Knapp, M., . . . Whitaker, R. (2013). Goal-orientated rehabilitation in early-stage dementia: study protocol for a multi-centre single-blind randomised controlled trial (GREAT). Trials, 14, 152. doi:10.1186/1745-6215-14-152

Clare, L., Linden, D. E., Woods, R. T., Whitaker, R., Evans, S. J., Parkinson, C. H., . . Yuen, K. S. (2010). Goaloriented cognitive rehabilitation for people with early-stage Alzheimer disease: a single-blind randomized controlled trial of clinical efficacy. American Journal of Geriatric Psychiatry, 18(10), 928939. doi:10.1097/JGP.0b013e3181d5792a 
Clarke, C. E., Patel, S., Ives, N., Rick, C. E., Woolley, R., Wheatley, K., . . Yao, G. (2016). Clinical effectiveness and cost-effectiveness of physiotherapy and occupational therapy versus no therapy in mild to moderate Parkinson's disease: a large pragmatic randomised controlled trial (PD REHAB). Health Technology Assessment, 20(63), 1-96.

Cleary, S., Kizar, S., Kalra, S., Johnston, W. (2008). Using active rehabilitation to decrease the risk of pneumonia in end-of-life ALS and dementia care. Canadian Nursing Home, 19(2), 4-10.

Colquhoun, H. L., Levac, D., O'Brien, K. K., Straus, S., Tricco, A. C., Perrier, L., . . Moher, D. (2014). Scoping reviews: time for clarity in definition, methods, and reporting. Journal of Clinical Epidemiology, 67(12), 1291-1294.

Croot, K., Nickels, L., Laurence, F., \& Manning, M. (2009). Impairment-and activity/participation-directed interventions in progressive language impairment: Clinical and theoretical issues. Aphasiology, 23(2), 125-160. doi:10.1080/02687030801943179

Dennison, L., Moss-Morris, R., Yardley, L., Kirby, S., \& Chalder, T. (2013). Change and processes of change within interventions to promote adjustment to multiple sclerosis: learning from patient experiences. Psychology and Health, 28(9), 973-992. doi:10.1080/08870446.2013.767904

Dewar, B.-K., Patterson, K., Wilson, B. A., \& Graham, K. S. (2009). Re-acquisition of person knowledge in semantic memory disorders. Neuropsychological Rehabilitation, 19(3), 383-421. doi:10.1080/09602010802278152

Diehl, J., Mayer, T., Förstl, H., \& Kurz, A. (2003). A support group for caregivers of patients with frontotemporal dementia. Dementia, 2(2), 151-161. doi:10.1177/1471301203002002002

Dipple, H., \& Evans, B. (1998). The Leicestershire Huntington's disease support group: a social network analysis. Health and Social Care in the Community, 6(4), 286-289. doi:10.1046/j.1365-2524.1998.00132.x

Disbrow, E. A., Russo, K. A., Higginson, C. I., Yund, E. W., Ventura, M. I., Zhang, L., . . Sigvardt, K. A. (2012). Efficacy of tailored computer-based neurorehabilitation for improvement of movement initiation in Parkinson's disease. Brain Research, 1452, 151-164. doi:10.1016/j.brainres.2012.02.073

Dlugonski, D., Motl, R. W., \& McAuley, E. (2011). Increasing physical activity in multiple sclerosis: replicating Internet intervention effects using objective and self-report outcomes. Journal of Rehabilitation Research and Development, 48(9), 1129-1136.

Dlugonski, D., Motl, R. W., Mohr, D. C., \& Sandroff, B. M. (2012). Internet-delivered behavioral intervention to increase physical activity in persons with multiple sclerosis: sustainability and secondary outcomes. Psychology, Health and Medicine, 17(6), 636-651. doi:10.1080/13548506.2011.652640

Dobkin, R. D., Allen, L. A., \& Menza, M. (2007). Cognitive-behavioral therapy for depression in Parkinson's disease: a pilot study. Movement Disorders, 22(7), 946-952. doi:10.1002/mds.21455

Dobkin, R. D., Menza, M., Allen, L. A., Gara, M. A., Mark, M. H., Tiu, J., . . Friedman, J. (2011). Cognitivebehavioral therapy for depression in Parkinson's disease: a randomized, controlled trial. American Journal of Psychiatry, 168(10), 1066-1074. doi:10.1176/appi.ajp.2011.10111669

Dobkin, R. D., Tröster, A. I., Rubino, J. T., Allen, L. A., Gara, M. A., Mark, M. H., \& Menza, M. (2014). Neuropsychological outcomes after psychosocial intervention for depression in Parkinson's disease. Journal of Neuropsychiatry and Clinical Neurosciences, 26(1), 57-63. doi:10.1176/appi.neuropsych.12120381

Dorsey, E. R., Voss, T. S., Shprecher, D. R., Deuel, L. M., Beck, C. A., Gardiner, I. F., . . Biglan, K. M. (2010). A U.S. survey of patients with Parkinson's disease: satisfaction with medical care and support groups. Movement Disorders, 25(13), 2128-2135. doi:10.1002/mds.23160

Dowling, G. A., Merrilees, J., Mastick, J., Chang, V. Y., Hubbard, E., \& Moskowitz, J. T. (2014). Life enhancing activities for family caregivers of people with frontotemporal dementia. Alzheimer Disease and Associated Disorders, 28(2), 175-181. doi:10.1097/WAD.0b013e3182a6b905

Dressel, K., Huber, W., Frings, L., Kümmerer, D., Saur, D., Mader, I., . . Abel, S. (2010). Model-oriented naming therapy in semantic dementia: a single-case fMRI study. Aphasiology, 24(12), 1537-1558. doi:10.1080/02687038.2010.500567

Eddy, C. M., Mahalingappa, S. S., \& Rickards, H. E. (2014). Putting things into perspective: the nature and impact of theory of mind impairment in Huntington's disease. European Archives of Psychiatry and Clinical Neuroscience, 264(8), 697-705. doi:10.1007/s00406-014-0498-4

Ehde, D. M., Elzea, J. L., Verrall, A. M., Gibbons, L. E., Smith, A. E., \& Amtmann, D. (2015). Efficacy of a telephone-delivered self-management intervention for persons with multiple sclerosis: a randomized controlled trial with a one-year follow-up. Archives of Physical Medicine and Rehabilitation, 96(11), 1945-1958. doi:10.1016/j.apmr.2015.07.015

Ernst, A., Blanc, F., Voltzenlogel, V., de Seze, J., Chauvin, B., \& Manning, L. (2013). Autobiographical memory in multiple sclerosis patients: assessment and cognitive facilitation. Neuropsychological Rehabilitation, 23(2), 161-181. doi:10.1080/09602011.2012.724355 
Eyssen, I. C. J. M., Steultjens, M. P. M., de Groot, V., Steultjens, E. M. J., Knol, D. L., Polman, C. H., \& Dekker, J. (2013). A cluster randomised controlled trial on the efficacy of client-centred occupational therapy in multiple sclerosis: good process, poor outcome. Disability and Rehabilitation, 35(19), 1636-1646. doi: $10.3109 / 09638288.2012 .748845$

Fernie, B. A., Kollmann, J., \& Brown, R. G. (2015). Cognitive behavioural interventions for depression in chronic neurological conditions: a systematic review. Journal of Psychosomatic Research, 78(5), 411-419.

Feys, P., Tytgat, K., Gijbels, D., De Groote, L., Baert, I., \& Van Asch, P. (2013). Effects of an 1-day education program on physical functioning, activity and quality of life in community living persons with multiple sclerosis. NeuroRehabilitation, 33(3), 439-448. doi:10.3233/NRE-130975

Fick, W., van der Borgh, J., Jansen, S., \& Koopmans, R. (2014). The effect of a lollipop on vocally disruptive behavior in a patient with frontotemporal dementia: a case-study. International Psychogeriatrics, 26(12), 2023-2026. doi:10.1017/S10410214000866

Fink, F., Rischkau, E., Butt, M., Klein, J., Eling, P., \& Hildebrandt, H. (2010). Efficacy of an executive function intervention programme in MS: a placebo-controlled and pseudo-randomized trial. Multiple Sclerosis, 16(9), 1148-1151. doi:10.1177/1352458510375440

Finlayson, M. (2005). Pilot study of an energy conservation education program delivered by telephone conference call to people with multiple sclerosis. NeuroRehabilitation, 20(4), 267-277.

Finlayson, M., Garcia, J. D., \& Preissner, K. (2008). Development of an educational programme for caregivers of people aging with multiple sclerosis. Occupational Therapy International, 15(1), 4-17. doi:10.1002/oti.243

Finlayson, M., Preissner, K., Cho, C., \& Plow, M. (2011). Randomized trial of a teleconference-delivered fatigue management program for people with multiple sclerosis. Multiple Sclerosis, 17(9), 1130-1140. doi:10.1177/1352458511404272

Fitzpatrick, L., Simpson, J., \& Smith, A. (2010). A qualitative analysis of mindfulness-based cognitive therapy $(\mathrm{MBCT})$ in Parkinson's disease. Psychology and Psychotherapy, 83(Pt 2), 179-192. doi:10.1348/147608309X471514

Frattali, C. (2004). An errorless learning approach to treating dysnomia in frontotemporal dementia. Journal of Medical Speech-Language Pathology, 12(3), xi-xi.

Frich, J. C., Røthing, M., \& Berge, A. R. (2014). Participants', caregivers', and professionals' experiences with a group-based rehabilitation program for Huntington's disease: a qualitative study. BMC Health Services Research, 14(1), 1. doi:10.1186/1472-6963-14-395

Gentry, T. (2008). PDAs as cognitive aids for people with multiple sclerosis. American Journal of Occupational Therapy, 62(1), 18. doi:10.5014/ajot.62.1.18

Ghahari, S., Packer, T. L., \& Passmore, A. E. (2009). Development, standardisation and pilot testing of an online fatigue self-management program. Disability and Rehabilitation, 31(21), 1762-1772. doi:10.1080/09638280902751956

Gil-Ruiz, N., Osorio, R. S., Cruz, I., Agüera-Ortiz, L., Olazarán, J., Sacks, H., . . Alzheimer Center Of The Queen Sofia Foundation Multidisciplinary Therapy, G. (2013). An effective environmental intervention for management of the 'mirror sign' in a case of probable Lewy body dementia. Neurocase, 19(1), 1-13. doi:10.1080/13554794.2011.633533

Giovannetti, T., Seligman, S. C., Britnell, P., Brennan, L., \& Libon, D. J. (2015). Differential effects of goal cues on everyday action errors in Alzheimer's disease versus Parkinson's disease dementia. Neuropsychology, 29(4), 592-602. doi:10.1037/neu0000167

Goldstein, L., Atkins, L., \& Leigh, P. (2002). Correlates of quality of life in people with motor neuron disease (MND). Amyotrophic Lateral Sclerosis and Other Motor Neuron Disorders, 3(3), 123-129. doi:10.1080/146608202760834120

Goodwin, L. S., \& Lan, L. (2014). Evaluation and delivery of ambulatory rehabilitation for people with Parkinson's disease. Reviews in Clinical Gerontology, 24(02), 122-138. doi:10.1017/S09592598713000257

Goretti, B., Portaccio, E., Zipoli, V., Razzolini, L., \& Amato, M. (2010). Coping strategies, cognitive impairment, psychological variables and their relationship with quality of life in multiple sclerosis. Neurological Sciences, 31(2), 227-230.

Gould, R. L., Coulson, M. C., Brown, R. G., Goldstein, L. H., Al-Chalabi, A., \& Howard, R. J. (2015). Psychotherapy and pharmacotherapy interventions to reduce distress or improve well-being in people with amyotrophic lateral sclerosis: A systematic review. Amyotrophic Lateral Sclerosis and Frontotemporal Degeneration, 16(5-6), 293-302. doi:10.3109/21678421.2015.1062515

Goverover, Y., Chiaravalloti, N. D., \& DeLuca, J. (2008). Self-generation to improve learning and memory of functional activities in persons with multiple sclerosis: meal preparation and managing finances. Archives of Physical Medicine and Rehabilitation, 89(8), 1514-1521. doi:10.1016/j.apmr.2007.11059 
Goverover, Y., Chiaravalloti, N. D., \& DeLuca, J. (2016). Brief International Cognitive Assessment for Multiple Sclerosis (BICAMS) and performance of everyday life tasks: actual reality. Multiple Sclerosis Journal, 22(4), 544-550.

Goverover, Y., Haas, S., \& DeLuca, J. (2016). Money management activities in persons with multiple sclerosis. Archives of Physical Medicine and Rehabilitation.

Graziano, F., Calandri, E., Borghi, M., \& Bonino, S. (2014). The effects of a group-based cognitive behavioral therapy on people with multiple sclerosis: a randomized controlled trial. Clinical Rehabilitation, 28(3), 264-274. doi:10.1177/0269215513501525

Hindle, J. V., Petrelli, A., Clare, L., \& Kalbe, E. (2013). Nonpharmacological enhancement of cognitive function in Parkinson's disease: a systematic review. Movement Disorders, 28(8), 1034-1049. doi:10.1002/mds.25377

Ho, A. K., Gilbert, A. S., Mason, S. L., Goodman, A. O., \& Barker, R. A. (2009). Health-related quality of life in Huntington's disease: which factors matter most? Movement Disorders, 24(4), 574-578.

Izzo, K. L., DiLorenzo, P., \& Roth, A. (1986). Rehabilitation in progressive supranuclear palsy: case report. Archives of Physical Medicine and Rehabilitation, 67(7), 473-476.

Jain, S., Dawson, J., Quinn, N. P., \& Playford, E. D. (2004). Occupational therapy in multiple system atrophy: a pilot randomized controlled trial. Movement Disorders, 19(11), 1360-1364.

Jefferies, E., Bott, S., Ehsan, S., \& Ralph, M. A. L. (2011). Phonological learning in semantic dementia. Neuropsychologia, 49(5), 1208-1218. doi:10.1016/j.neuropsychologia.2011.01.036

Jiménez-Murcia, S., Bove, F. I., Israel, M., Steiger, H., Fernández-Aranda, F., Alvarez-Moya, E., . . Menchón, J. M. (2012). Cognitive-behavioral therapy for pathological gambling in Parkinson's disease: a pilot controlled study. European Addiction Research, 18(6), 265-274. doi:10.1159/000337442

Jokel, R., \& Anderson, N. D. (2012). Quest for the best: effects of errorless and active encoding on word relearning in semantic dementia. Neuropsychological Rehabilitation, 22(2), 187-214. doi:10.1080/09602011.2011.639626

Jokel, R., Rochon, E., \& Anderson, N. D. (2010). Errorless learning of computer-generated words in a patient with semantic dementia. Neuropsychological Rehabilitation, 20(1), 16-41. doi:10.1080/09602010902879859

Jokel, R., Rochon, E., \& Leonard, C. (2006). Treating anomia in semantic dementia: improvement, maintenance, or both? Neuropsychological Rehabilitation, 16(3), 241-256. doi:10.1080/09602010500176757

Kaiser, J., Perelmouter, J., Iversen, I. H., Neumann, N., Ghanayim, N., Hinterberger, T., . . Birbaumer, N. (2001). Self-initiation of EEG-based communication in paralyzed patients. Clinical Neurophysiology, 112(3), 551-554.

Kasarkis, E. J., Elza, T. A., Bishop, N. G., \& Spears, A. C. (1997). The amyotrophic lateral sclerosis (ALS) support network of Kentucky: an informational support group using interactive video. Journal of the Neurological Sciences, 152 Suppl 1, S90-S92.

Klaren, R. E., Hubbard, E. A., \& Motl, R. W. (2014). Efficacy of a behavioral intervention for reducing sedentary behavior in persons with multiple sclerosis: a pilot examination. American Journal of Preventive Medicine, 47(5), 613-616. doi:10.1016/j.amepre.2014.05.036

Klasner, E., \& Yorkston, K. (2001). Linguistic and cognitive supplementation strategies as augmentative and alternative communication techniques in huntington's disease: Case report. Augmentative and Alternative Communication, 17(3), 154-160. doi:10.1080/714043379

Knoop, H., van Kessel, K., \& Moss-Morris, R. (2012). Which cognitions and behaviours mediate the positive effect of cognitive behavioural therapy on fatigue in patients with multiple sclerosis? Psychological Medicine, 42(1), 205-213. doi:10.1017/S0033291711000924

Korostil, M., \& Feinstein, A. (2007). Anxiety disorders and their clinical correlates in multiple sclerosis patients. Multiple Sclerosis Journal, 13(1), 67-72. doi:10.1177/1352458506071161

Kortte, K. B., \& Rogalski, E. J. (2013). Behavioural interventions for enhancing life participation in behavioural variant frontotemporal dementia and primary progressive aphasia. International Review of Psychiatry, 25(2), 237-245. doi:10.3109/09540261.2012.751017

Kübler, A., Neumann, N., Kaiser, J., Kotchoubey, B., Hinterberger, T., \& Birbaumer, N. P. (2001). Braincomputer communication: self-regulation of slow cortical potentials for verbal communication. Archives of Physical Medicine and Rehabilitation, 82(11), 1533-1539. doi:10.1053/apmr/201.26621

Labiano-Fontcuberta, A., Mitchell, A. J., Moreno-García, S., \& Benito-León, J. (2014). Cognitive impairment in patients with multiple sclerosis predicts worse caregiver's health-related quality of life. Multiple Sclerosis Journal, 20(13), 1769-1779.

Langenbahn, D. M., Ashman, T., Cantor, J., \& Trott, C. (2013). An evidence-based review of cognitive rehabilitation in medical conditions affecting cognitive function. Archives of Physical Medicine and Rehabilitation, 94(2), 271-286. doi:10.1016/j.apmr.2012.09.011 
Levac, D., Colquhoun, H., \& O'Brien, K. K. (2010). Scoping studies: advancing the methodology. Implementation Science, 5(1), 1.

Lexell, E. M., Flansbjer, U.-B., \& Lexell, J. (2014). Self-perceived performance and satisfaction with performance of daily activities in persons with multiple sclerosis following interdisciplinary rehabilitation. Disability and Rehabilitation, 36(5), 373-378. doi:10.3109/09638288.2013.797506

Lincoln, N., Dent, A., \& Harding, J. (2003). Treatment of cognitive problems for people with multiple sclerosis. International Journal of Therapy and Rehabilitation, 10(9).

Lincoln, N., Dent, A., Harding, J., Weyman, N., Nicholl, C., Blumhardt, L., \& Playford, E. (2002). Evaluation of cognitive assessment and cognitive intervention for people with multiple sclerosis. Journal of Neurology, Neurosurgery and Psychiatry, 72(1), 93-98. doi:10.1136/jnnp.72.1.93

Mäntynen, A., Rosti-Otajärvi, E., Koivisto, K., Lilja, A., Huhtala, H., \& Hämäläinen, P. (2014). Neuropsychological rehabilitation does not improve cognitive performance but reduces perceived cognitive deficits in patients with multiple sclerosis: a randomised, controlled, multi-centre trial. Multiple Sclerosis Journal, 20(1), 99-107.

Martin, N. H., Landau, S., Janssen, A., Lyall, R., Higginson, I., Burman, R., . . Shaw, C. E. (2014). Psychological as well as illness factors influence acceptance of non-invasive ventilation (NIV) and gastrostomy in amyotrophic lateral sclerosis (ALS): a prospective population study. Amyotrophic Lateral Sclerosis and Frontotemporal Degeneration, 15(5-6), 376-387. doi:10.3109/21678421.2014.886700

Mathiowetz, V. G., Finlayson, M. L., Matuska, K. M., Chen, H. Y., \& Luo, P. (2005). Randomized controlled trial of an energy conservation course for persons with multiple sclerosis. Multiple Sclerosis, 11(5), 592601.

Mathiowetz, V. G., Matuska, K. M., Finlayson, M. L., Luo, P., \& Chen, H. Y. (2007). One-year follow-up to a randomized controlled trial of an energy conservation course for persons with multiple sclerosis. International Journal of Rehabilitation Research, 30(4), 305-313.

Mathiowetz, V. G., Matuska, K. M., \& Murphy, M. E. (2001). Efficacy of an energy conservation course for persons with multiple sclerosis. Archives of Physical Medicine and Rehabilitation, 82(4), 449-456.

Mattern, J. M., \& Kane, E. (2007). Huntington's disease client as activity leader. Clinical Gerontologist, 30(4), 93-100. doi:10.1300/j018v3on04-07

McKinnon, C., O'Connor, C., Savage, S., Hodges, J., \& Mioshi, E. (2013). Qualitative results of a structured group program for carers of people with frontotemporal dementia. International Journal of Geriatric Psychiatry, 28(2), 217-218. doi:10.1002/gps.3813

Meek, C., Morgan, E., Walker, M. F., Furmston, A., Aragon, A., Birleson, A., . . . Sackley, C. M. (2010). Occupational therapy to optimise independence in Parkinson's disease: the designing and recording of a randomised controlled trial intervention. British Journal of Occupational Therapy, 73(4), 178-185. doi: $10.4276 / 030802210 X 12706313444027$

Meier, S. L., Charleston, A. J., \& Tippett, L. J. (2010). Cognitive and behavioural deficits associated with the orbitomedial prefrontal cortex in amyotrophic lateral sclerosis. Brain, 133(11), 3444-3457.

Merrilees, J., Klapper, J., Murphy, J., Lomen-Hoerth, C., \& Miller, B. L. (2010). Cognitive and behavioral challenges in caring for patients with frontotemporal dementia and amyotrophic lateral sclerosis. Amyotrophic Lateral Sclerosis, 11(3), 298-302.

Miller, D. M., Moore, S. M., Fox, R. J., Atreja, A., Fu, A. Z., Lee, J.-C., . . Rudick, R. A. (2011). Web-based self-management for patients with multiple sclerosis: a practical, randomized trial. Telemedicine Journal and E-Health, 17(1), 5-13. doi:10.1089/tmj.2010.0133

Mioshi, E., McKinnon, C., Savage, S., O’Connor, C. M., \& Hodges, J. R. (2013). Improving burden and coping skills in frontotemporal dementia caregivers: a pilot study. Alzheimer Disease and Associated Disorders, 27(1), 84-86. doi:10.1097/WAD.0bo13e31824a7f5b

Mohr, D. C., Classen, C., \& Barrera, M., Jr. (2004). The relationship between social support, depression and treatment for depression in people with multiple sclerosis. Psychological Medicine, 34(3), 533-541. doi:10.1017/s0033291703001235

Mohr, D. C., Hart, S., \& Vella, L. (2007). Reduction in disability in a randomized controlled trial of telephoneadministered cognitive-behavioral therapy. Health Psychology, 26(5), 554. doi:10.1037/02786133.26.5.554

Mohr, D. C., Hart, S. L., \& Goldberg, A. (2003). Effects of treatment for depression on fatigue in multiple sclerosis. Psychosomatic Medicine, 65(4), 542-547. doi:10.1097/01.psy.0000074757.11682.96

Mohr, D. C., Hart, S. L., Julian, L., Catledge, C., Honos-Webb, L., Vella, L., \& Tasch, E. T. (2005). Telephoneadministered psychotherapy for depression. Archives of General Psychiatry, 62(9), 1007-1014. doi:10.1001/archpsyc.62.9.1007

Morley, D., Dummett, S., Peters, M., Kelly, L., Hewitson, P., Dawson, J., . . . Jenkinson, C. (2012). Factors influencing quality of life in caregivers of people with Parkinson's disease and implications for clinical guidelines. Parkinson's Disease, 2012. 
Morris, R., \& Becker, J. (2004). Cognitive Neuropsychology of Alzheimer's disease. Oxford: Oxford University Press.

Moss-Morris, R., McCrone, P., Yardley, L., van Kessel, K., Wills, G., \& Dennison, L. (2012). A pilot randomised controlled trial of an Internet-based cognitive behavioural therapy self-management programme (MS Invigor8) for multiple sclerosis fatigue. Behaviour Research and Therapy, 50(6), 415-421. doi:10.1016/j.brat.2012.03.001

Motl, R. W., \& Dlugonski, D. (2011). Increasing physical activity in multiple sclerosis using a behavioral intervention. Behavioral Medicine, 37(4), 125-131. doi:10.1080/08964289.2011.636769

Motl, R. W., Dlugonski, D., Pilutti, L. A., \& Klaren, R. E. (2015). Does the effect of a physical activity behavioral intervention vary by characteristics of people with multiple sclerosis? International Journal of MS Care, 17(2), 65-72. doi:10.7224/1537-2073.2014-016

Motl, R. W., Dlugonski, D., Wójcicki, T. R., McAuley, E., \& Mohr, D. C. (2011). Internet intervention for increasing physical activity in persons with multiple sclerosis. Multiple Sclerosis, 17(1), 116-128. doi:10.1177/1352458510383148

Mulligan, H., Arps, G., Bancroft, N., Mountfort, R., \& Polkinghorne, A. (2011). 'Living Well with Parkinson's': Evaluation of a programme to promote self-management. Journal of Nursing and Healthcare of Chronic Illness, 3(3), 222-233. doi:10.1111/j.1752-9824.2011.01082.x

Mulligan, H., Treharne, G. J., Hale, L. A., \& Smith, C. (2013). Combining self-help and professional help to minimize barriers to physical activity in persons with multiple sclerosis: a trial of the "Blue Prescription" approach in New Zealand. Journal of Neurologic Physical Therapy, 37(2), 51-57. doi:10.1097/NPT.0b013e318292799e

Navipour, H., Madani, H., Mohebbi, M. R., Navipour, R., Roozbayani, P., \& Paydar, A. (2006). Improved fatigue in individuals with multiple sclerosis after participating in a short-term self-care programme. NeuroRehabilitation, 21(1), 37-41.

Neumann, N., Kübler, A., Kaiser, J., Hinterberger, T., \& Birbaumer, N. (2003). Conscious perception of brain states: mental strategies for brain-computer communication. Neuropsychologia, 41(8), 1028-1036.

Newhart, M., Davis, C., Kannan, V., Heidler-Gary, J., Cloutman, L., \& Hillis, A. E. (2009). Therapy for naming deficits in two variants of primary progressive aphasia. Aphasiology, 23(7-8), 823-834. doi:10.1080/02687030802661762

Ng, A., Kennedy, P., Hutchinson, B., Ingram, A., Vondrell, S., Goodman, T., \& Miller, D. (2013). Self-efficacy and health status improve after a wellness program in persons with multiple sclerosis. Disability and Rehabilitation, 35(12), 1039-1044. doi:10.3109/09638288.2012.717586

Nordin, L., \& Rorsman, I. (2012). Cognitive behavioural therapy in multiple sclerosis: a randomized controlled pilot study of acceptance and commitment therapy. Journal of Rehabilitation Medicine, 44(1), 87-90.

O'Connell, M. E., Crossley, M., Cammer, A., Morgan, D., Allingham, W., Cheavins, B., . . Morgan, E. (2014). Development and evaluation of a telehealth videoconferenced support group for rural spouses of individuals diagnosed with atypical early-onset dementias. Dementia, 13(3), 382-395. doi: $10.1177 / 1471301212474143$

O'Connor, C. M., Clemson, L., Brodaty, H., Gitlin, L. N., Piguet, O., \& Mioshi, E. (2016). Enhancing caregivers' understanding of dementia and tailoring activities in frontotemporal dementia: two case studies. Disability and Rehabilitation, 38(7), 704-714. doi:10.3109/09638288.2015.1055375

O'Hara, L., Cadbury, H., De Souza, L., \& Ide, L. (2002). Evaluation of the effectiveness of professionally guided self-care for people with multiple sclerosis living in the community: a randomized controlled trial. Clinical Rehabilitation, 16(2), 119-128.

Palmieri, A., Sorarù, G., Albertini, E., Semenza, C., Vottero-Ris, F., D’Ascenzo, C., . . Angelini, C. (2010). Psychopathological features and suicidal ideation in amyotrophic lateral sclerosis patients. Neurological Sciences, 31(6), 735-740.

Pérez, A. I. G., \& Dapueto, J. J. (2014). Case report of a computer-assisted psychotherapy of a patient with ALS. International Journal of Psychiatry in Medicine, 48(3), 229-233.

Pham, M. T., Rajić, A., Greig, J. D., Sargeant, J. M., Papadopoulos, A., \& McEwen, S. A. (2014). A scoping review of scoping reviews: advancing the approach and enhancing the consistency. Research Synthesis Methods, 5(4), 371-385.

Piira, A., Van Walsem, M. R., Mikalsen, G., Nilsen, K. H., Knutsen, S., \& Frich, J. C. (2013). Effects of a one year intensive multidisciplinary rehabilitation program for patients with Huntington's disease: a

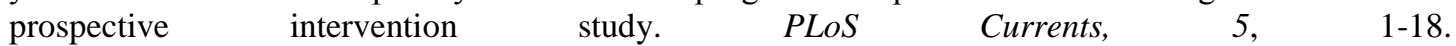
doi:10.1371/currents.hd.9504af71e0d187830c394be47027

Pilutti, L. A., Dlugonski, D., Sandroff, B. M., Klaren, R., \& Motl, R. W. (2014). Randomized controlled trial of a behavioral intervention targeting symptoms and physical activity in multiple sclerosis. Multiple Sclerosis, 20(5), 594-601. doi:10.1177/1352458513503391 
Pirogovsky, E., Schiehser, D. M., Obtera, K. M., Burke, M. M., Lessig, S. L., Song, D. D., . . Filoteo, J. V. (2014). Instrumental activities of daily living are impaired in Parkinson's disease patients with mild cognitive impairment. Neuropsychology, 28(2), 229.

Plow, M., Bethoux, F., Mai, K., \& Marcus, B. (2014). A formative evaluation of customized pamphlets to promote physical activity and symptom self-management in women with multiple sclerosis. Health Education Research, 29(5), 883-896. doi:10.1093/her/cyu034

Plow, M., Bethoux, F., McDaniel, C., McGlynn, M., \& Marcus, B. (2014). Randomized controlled pilot study of customized pamphlets to promote physical activity and symptom self-management in women with multiple sclerosis. Clinical Rehabilitation, 28(2), 139-148. doi:10.1177/0269215513494229

Pretzer-Aboff, I., Galik, E., \& Resnick, B. (2011). Feasibility and impact of a function focused care intervention for Parkinson's disease in the community. Nursing Research, 60(4), 276-283. doi:10.1097/NNR.0b013e318221bb0f

Rae-Grant, A. D., Turner, A. P., Sloan, A., Miller, D., Hunziker, J., \& Haselkorn, J. K. (2011). Self-management in neurological disorders: systematic review of the literature and potential interventions in multiple sclerosis care. Journal of Rehabilitation Research and Development, 48(9), 1087. doi:10.1182/jrrd.2010.08.0159

Ready, R. E., Mathews, M., Leserman, A., \& Paulsen, J. S. (2008). Patient and caregiver quality of life in Huntington's disease. Movement Disorders, 23(5), 721-726.

Regan, J., De Roiste, M., Greene, J., Murray, D. B., Donnelly, S., Hill, F., . . . Murphy, R. P. (2008). A multidisciplinary education and support group for individuals with MND and their carers. Rehabilitation and Therapy Research Society, 13(2), 133.

Rietberg, M. B., van Wegen, E. E. H., Eyssen, I. C. J. M., \& Kwakkel, G. (2014). Effects of multidisciplinary rehabilitation on chronic fatigue in multiple sclerosis: a randomized controlled trial. PLoS One, 9(9), 19. doi:10.1371/journal.pone.0107710

Rigby, S. A., Thornton, E. W., \& Young, C. A. (2008). A randomized group intervention trial to enhance mood and self-efficacy in people with multiple sclerosis. British Journal of Health Psychology, 13(4), 619631. doi:10.1348/135910707x241505

Robinson, S., Druks, J., Hodges, J., \& Garrard, P. (2009). The treatment of object naming, definition, and object use in semantic dementia: the effectiveness of errorless learning. Aphasiology, 23(6), 749-775. doi:10.1080/02687030802235195

Rosti-Otajärvi, E., Mäntynen, A., Koivisto, K., Huhtala, H., \& Hämäläinen, P. (2013). Patient-related factors may affect the outcome of neuropsychological rehabilitation in multiple sclerosis. Journal of the Neurological Sciences, 334(1-2), 106-111. doi:10.1016/j.jns.2013.07.2520

Rosti-Otajärvi, E. M., \& Hämäläinen, P. I. (2014). Neuropsychological rehabilitation for multiple sclerosis. Cochrane Database of Systematic Reviews. doi:10.1002/14651858.CD009131.pub3

Salminen, A.-L., Kanelisto, K. J., \& Karhula, M. E. (2014). What components of rehabilitation are helpful from the perspective of individuals with multiple sclerosis? Disability and Rehabilitation, 36(23), 1983-1989. doi:10.3109/09638288.2014.885092

Sandroff, B. M., Klaren, R. E., Pilutti, L. A., Dlugonski, D., Benedict, R. H. B., \& Motl, R. W. (2014). Randomized controlled trial of physical activity, cognition, and walking in multiple sclerosis. Journal of Neurology, 261(2), 363-372. doi:10.1007/s00415-013-7204-8

Savage, S. A., Ballard, K. J., Piguet, O., \& Hodges, J. R. (2013). Bringing words back to mind - improving word production in semantic dementia. Cortex, 49(7), 1823-1832. doi:10.1016/j.cortex.2012.09.014

Savage, S. A., Piguet, O., \& Hodges, J. R. (2014). Giving words new life: generalization of word retraining outcomes in semantic dementia. Journal of Alzheimer's Disease, 40(2), 309-317. doi:10.3233/JAD131826

Savage, S. A., Piguet, O., \& Hodges, J. R. (2015). Cognitive intervention in semantic dementia: maintaining words over time. Alzheimer Disease and Associated Disorders, 29(1), 55-62. doi:10.1097/WAD.0000000000000053

Schrag, A., Hovris, A., Morley, D., Quinn, N., \& Jahanshahi, M. (2006). Caregiver-burden in Parkinson's disease is closely associated with psychiatric symptoms, falls, and disability. Parkinsonism and Related Disorders, 12(1), 35-41.

Schrag, A., Jahanshahi, M., \& Quinn, N. (2000). What contributes to quality of life in patients with Parkinson's disease? Journal of Neurology, Neurosurgery and Psychiatry, 69(3), 308-312.

Shah, S. P., Glenn, G. L., Hummel, E. M., Hamilton, J. M., Martine, R. R., Duda, J. E., \& Wilkinson, J. R. (2015). Caregiver tele-support group for Parkinson's disease: a pilot study. Geriatric Nursing, 36(3), 207-211. doi:10.1016/j.gerinurse.2015.02.002

Shatil, E., Metzer, A., Horvitz, O., \& Miller, A. (2010). Home-based personalized cognitive training in MS patients: a study of adherence and cognitive performance. NeuroRehabilitation, 26(2), 143-153. 
Sheppard, S. C., Forsyth, J. P., Hickling, E. J., \& Bianchi, J. (2010). A novel application of acceptance and commitment therapy for psychosocial problems associated with multiple sclerosis: results from a halfday workshop intervention. International Journal of MS Care, 12(4), 200-206. doi:10.7224/1537-207312.4 .200

Shevil, E., \& Finlayson, M. (2009). Process evaluation of a self-management cognitive program for persons with multiple sclerosis. Patient Education and Counseling, 76(1), 77-83. doi:10.1016/j.pec.2008.11.007

Shevil, E., \& Finlayson, M. (2010). Pilot study of a cognitive intervention program for persons with multiple sclerosis. Health Education Research, 25(1), 41-53. doi:10.1093/her/cyp037

Siegert, R., \& Abernethy, D. (2005). Depression in multiple sclerosis: a review. Journal of Neurology, Neurosurgery \& Psychiatry, 76(4), 469-475. doi:10.1136/jnnp.2004.054635

Silver, A. (2003). Cognitive-behavioural therapy with a Huntington's gene positive patient. Patient Education and Counseling, 49(2), 133-138. doi:10.1016/s0738-3991(02)00070-8

Slaughter, J. R., Martens, M. P., \& Slaughter, K. A. (2001). Depression and Huntington's disease: prevalence, clinical manifestations, etiology, and treatment. CNS spectrums, 6(4), 306-308,325-326. doi:10.1017/S109285290002201X

Smith, C. M., Hale, L. A., Mulligan, H. F., \& Treharne, G. J. (2013). Participant perceptions of a novel physiotherapy approach ("Blue Prescription") for increasing levels of physical activity in people with multiple sclerosis: a qualitative study following intervention. Disability and Rehabilitation, 35(14), 1174-1181. doi:10.3109/09638288.2012.723792

Snowden, J. S., Kindell, J., Thompson, J. C., Richardson, A. M., \& Neary, D. (2012). Progressive aphasia presenting with deep dyslexia and dysgraphia. Cortex, 48(9), 1234-1239. doi:10.1016/j.cortex.2012.02.010

Snowden, J. S., \& Neary, D. (2002). Relearning of verbal labels in semantic dementia. Neuropsychologia, 40(10), 1715-1728. doi:10.1016/S0028-3932(02)00031-3

Stuifbergen, A. K., Becker, H., Blozis, S., Timmerman, G., \& Kullberg, V. (2003). A randomized clinical trial of a wellness intervention for women with multiple sclerosis. Archives of Physical Medicine and Rehabilitation, 84(4), 467-476.

Stuifbergen, A. K., Becker, H., Perez, F., Morison, J., Kullberg, V., \& Todd, A. (2012). A randomized controlled trial of a cognitive rehabilitation intervention for persons with multiple sclerosis. Clinical Rehabilitation, 26(10), 882-893. doi:10.1177/0269215511434997

Stuifbergen, A. K., Becker, H., Timmerman, G. M., \& Kullberg, V. (2003). The use of individualized goal setting to facilitate behavior change in women with multiple sclerosis. Journal of Neuroscience Nursing, 35(2), 94.

Sturkenboom, I. H., Graff, M. J., Borm, G. F., Veenhuizen, Y., Bloem, B. R., Munneke, M., \& Nijhuis-van der Sanden, M. W. (2013). The impact of occupational therapy in Parkinson's disease: a randomized controlled feasibility study. Clinical Rehabilitation, 27(2), 99-112.

Suárez-González, A., Heredia, C. G., Savage, S. A., Gil-Néciga, E., García-Casares, N., Franco-Macías, E., . . . Caine, D. (2015). Restoration of conceptual knowledge in a case of semantic dementia. Neurocase, 21(3), 309-321. doi:10.1080/13554794.2014.892624

Sullivan, F. R., Bird, E. D., Alpay, M., \& Cha, J.-H. J. (2001). Remotivation therapy and Huntington's disease. Journal of Neuroscience Nursing, 33(3), 136-142.

Thomas, S., Thomas, P. W., Kersten, P., Jones, R., Green, C., Nock, A., . . Hillier, C. (2013). A pragmatic parallel arm multi-centre randomised controlled trial to assess the effectiveness and cost-effectiveness of a groupbased fatigue management programme (FACETS) for people with multiple sclerosis. Journal of Neurology, Neurosurgery and Psychiatry, 84(10), 1092-1099. doi:10.1136/jnnp-2012-303816

Thompson, J. A., Cruickshank, T., Penailillo, L., Lee, J., Newton, R., Barker, R., \& Ziman, M. R. (2013). The effects of multidisciplinary rehabilitation in patients with early-to-middle-stage Huntington's disease: a pilot study. European Journal of Neurology, 20(9), 1325-1329. doi:10.1111/ene.12053

Traynor, B. J., Alexander, M., Corr, B., Frost, E., \& Hardiman, O. (2003). Effect of a multidisciplinary amyotrophic lateral sclerosis (ALS) clinic on ALS survival: a population based study, 1996-2000. Journal of Neurology, Neurosurgery and Psychiatry, 74(9), 1258-1261.

Twomey, F., \& Robinson, K. (2010). Pilot study of participating in a fatigue management programme for clients with multiple sclerosis. Disability and Rehabilitation, 32(10), 791-800. doi:10.3109/09638281003656578

van Kessel, K., Moss-Morris, R., Willoughby, E., Chalder, T., Johnson, M. H., \& Robinson, E. (2008). A randomized controlled trial of cognitive behavior therapy for multiple sclerosis fatigue. Psychosomatic Medicine, 70(2), 205-213. doi:10.1097/psy.0b013e3181643065

Vandenbossche, J., Deroost, N., Soetens, E., Spildooren, J., Vercruysse, S., Nieuwboer, A., \& Kerckhofs, E. (2011). Freezing of gait in Parkinson disease is associated with impaired conflict resolution. Neurorehabilitation and Neural Repair, 25(8), 765-773. doi:10.1177/1545968311403493 
Yokota, O., Fujisawa, Y., Takahashi, J., Terada, S., Ishihara, T., Nakashima, H., . . Sasaki, K. (2006). Effects of group-home care on behavioral symptoms, quality of life, and psychotropic drug use in patients with frontotemporal dementia. Journal of the American Medical Directors Association, 7(5), 335-337.

Zinzi, P., Salmaso, D., De Grandis, R., Graziani, G., Maceroni, S., Bentivoglio, A., . . Jacopini, G. (2007). Effects of an intensive rehabilitation programme on patients with Huntington's disease: a pilot study. Clinical Rehabilitation, 21(7), 603-613. doi:10.1177/0269215507075495 
Table 1. Cognitive, behavioural and emotional features that may arise in each of the five PNCs

\begin{tabular}{|c|c|c|c|c|c|}
\hline Possible features: & PDs & MS & FTDs & HD & MND \\
\hline Executive function impairment & $\sqrt{ }$ & $\sqrt{ }$ & $\sqrt{ }$ & $\sqrt{ }$ & $\sqrt{ }$ \\
\hline Attention impairment & $\sqrt{ }$ & & $\sqrt{ }$ & $\sqrt{ }$ & $\sqrt{ }$ \\
\hline Information processing impairment & $\sqrt{ }$ & $\sqrt{ }$ & $\sqrt{ }$ & $\sqrt{ }$ & \\
\hline Working memory impairment & $\sqrt{ }$ & & $\sqrt{ }$ & $\sqrt{ }$ & $\sqrt{ }$ \\
\hline Episodic memory impairment & $\sqrt{ }$ & $\sqrt{ }$ & $\sqrt{ }$ & $\sqrt{ }$ & $\sqrt{ }$ \\
\hline Language and semantic impairment & & & $\sqrt{ }$ & $\sqrt{ }$ & $\sqrt{ }$ \\
\hline Visuospatial perception impairment & $\sqrt{ }$ & & & $\sqrt{ }$ & \\
\hline Delusions and hallucinations & $\sqrt{ }$ & & $\sqrt{ }$ & $\sqrt{ }$ & $\sqrt{ }$ \\
\hline Behavioural issues & $\sqrt{ }$ & & $\sqrt{ }$ & $\sqrt{ }$ & $\sqrt{ }$ \\
\hline Apathy & $\sqrt{ }$ & $\sqrt{ }$ & $\sqrt{ }$ & $\sqrt{ }$ & $\sqrt{ }$ \\
\hline Depression and anxiety & $\sqrt{ }$ & $\sqrt{ }$ & $\sqrt{ }$ & $\sqrt{ }$ & $\sqrt{ }$ \\
\hline
\end{tabular}


Table 2. Search terms used in the scoping review

$\underline{\text { Population-related search terms }}$

Huntington*

"Frontotemporal Dementia*” OR "Behavioural Variant Frontotemporal Dementia*” OR

"Semantic Dementia*” OR "Progressive Non Fluent Aphasia*” OR "Progressive Non-Fluent Aphasia*” OR "Frontotemporal Logopenic Aphasia*” OR “bevFTD” OR "FTD”

"Motor Neuron" OR MND OR ALS OR “Amyotrophic Lateral Sclerosis" OR "Lou Gehrig*” OR “Progressive Bulbar Pals*” OR "Progressive Muscular Atroph*” OR "Primary Lateral Sclerosis" OR “Anterior Horn Cell*” OR "Mill* Syndrome*”

"Multiple Sclerosis” OR “Clinically Isolated Syndrome” OR "Radiologically Isolated Syndrome"

Parkinson* OR "Progressive Supranuclear Palsy” OR “Multiple System Atrophy” OR "Corticobasal Degeneration" OR "Lewy Body Dementia*”

"Progressive Supranuclear Palsy” OR “Multiple System Atrophy” OR “Corticobasal Degeneration" OR "Lewy Body Dementia*”

$\underline{\text { Intervention-related search terms }}$

Intervention* OR Treatment* OR Therap* OR "Randomised Control* Trial*” OR

"Intervention* Stud*” OR Rehabilitation OR Remediation OR Retraining OR "Single case*" OR "Support group*” OR Psychoeducation OR Education OR "Self-management” OR Advice 
Table 3. Overview of studies included in the scoping review for each PND

(a) By research design

\begin{tabular}{lcccccc} 
& $\begin{array}{c}\text { MS } \\
(\mathrm{n}=74)\end{array}$ & $\begin{array}{c}\text { PDs } \\
(\mathrm{n}=19)\end{array}$ & $\begin{array}{c}\text { FTD } \\
(\mathrm{n}=27)\end{array}$ & $\begin{array}{c}\text { HD } \\
(\mathrm{n}=10)\end{array}$ & $\begin{array}{c}\text { MND } \\
(\mathrm{n}=10)\end{array}$ & $\begin{array}{c}\text { Total } \\
(\mathrm{n}=140)\end{array}$ \\
\hline $\mathrm{RCT}$ & 31 & 3 & 1 & 0 & 0 & 35 \\
$\begin{array}{l}\text { Secondary analysis of } \\
\text { RCT }\end{array}$ & 11 & 1 & 0 & 0 & 2 & 14 \\
$\begin{array}{l}\text { Non-randomised group } \\
\text { designs }\end{array}$ & 22 & 10 & 3 & 5 & 2 & 42 \\
$\begin{array}{l}\text { Single case designs or case } \\
\text { series }\end{array}$ & 3 & 1 & 21 & 3 & 4 & 32 \\
\begin{tabular}{l} 
Qualitative evaluation \\
\hline
\end{tabular} & 7 & 4 & 2 & 2 & 2 & 17 \\
\hline
\end{tabular}

(b) By type

\begin{tabular}{lcccccc} 
& $\begin{array}{c}\text { MS } \\
(\mathrm{n}=74)\end{array}$ & $\begin{array}{c}\text { PDs } \\
(\mathrm{n}=19)\end{array}$ & $\begin{array}{c}\text { FTD } \\
(\mathrm{n}=27)\end{array}$ & $\begin{array}{c}\text { HD } \\
(\mathrm{n}=10)\end{array}$ & $\begin{array}{c}\text { MND } \\
(\mathrm{n}=10)\end{array}$ & $\begin{array}{c}\text { Total } \\
(\mathrm{n}=140)\end{array}$ \\
\hline $\begin{array}{l}\text { Cognitive rehabilitation } \\
\text { Psychotherapy }\end{array}$ & 21 & 9 & 21 & 7 & 5 & 63 \\
Self-management & 17 & 5 & 1 & 2 & 3 & 28 \\
Carer interventions & 36 & 4 & 0 & 0 & 2 & 42 \\
\hline
\end{tabular}


Table 4. Studies included in the review

\section{(a) Cognitive rehabilitation}

\begin{tabular}{|c|c|c|c|c|c|}
\hline Authors \& Date & Design & Sample & Intervention & Aims & Key findings \\
\hline \multicolumn{6}{|c|}{ Fronto-temporal dementia (FTD) including semantic dementia (SD) - 22 studies } \\
\hline Bier et al. (2009) & $\begin{array}{l}\text { Case study, pre-post- } \\
\text { follow up }\end{array}$ & $\begin{array}{l}1 \text { person with } \\
\text { SD, } 5 \\
\text { controls }\end{array}$ & Spaced retrieval & $\begin{array}{l}\text { Explore formal semantic } \\
\text { therapy }\end{array}$ & $\begin{array}{l}\text { Better on trained } \\
\text { items. Maintained at } 5 \\
\text { weeks. No } \\
\text { generalisation. }\end{array}$ \\
\hline Bier et al. (2011) & $\begin{array}{l}\text { Case study, pre- } \\
\text { post- follow up }\end{array}$ & $\begin{array}{l}1 \text { person with } \\
\text { SD }\end{array}$ & $\begin{array}{l}\text { Ecological approach } \\
\text { CR }\end{array}$ & Explore effectiveness & $\begin{array}{l}\text { Cooked more } \\
\text { independently and } \\
\text { initiating more } \\
\text { cooking. }\end{array}$ \\
\hline $\begin{array}{l}\text { Bier, Brambati, et } \\
\text { al. (2015) }\end{array}$ & Case study & $\begin{array}{l}1 \text { person with } \\
\text { SD }\end{array}$ & Ecological CR & $\begin{array}{l}\text { Assess ability to learn new } \\
\text { technologies }\end{array}$ & $\begin{array}{l}\text { At 6-month follow- } \\
\text { many technology } \\
\text { functions still used. }\end{array}$ \\
\hline $\begin{array}{l}\text { Bier, Paquette, } \\
\text { and Macoir } \\
(2015)\end{array}$ & Case study & $\begin{array}{l}1 \text { person with } \\
\text { SD }\end{array}$ & $\mathrm{CR}$ & $\begin{array}{l}\text { Assess baseline use of } \\
\text { compensations and ability to } \\
\text { learn new technologies }\end{array}$ & $\begin{array}{l}\text { With an errorless } \\
\text { learning approach, he } \\
\text { learnt to effectively } \\
\text { use } 10 \text { smartphone } \\
\text { functions. }\end{array}$ \\
\hline $\begin{array}{l}\text { Dewar et al. } \\
\text { (2009) }\end{array}$ & $\begin{array}{l}3 \text { cases with HSE, } 1 \\
\text { case with SD, pre- } \\
\text { post }\end{array}$ & $\begin{array}{l}4 \text { people with } \\
\text { SD }\end{array}$ & $\begin{array}{l}\text { Mnemonics and } \\
\text { errorless learning for } \\
\text { relearning semantic } \\
\text { information }\end{array}$ & $\begin{array}{l}\text { Explored relearning of } \\
\text { semantic knowledge }\end{array}$ & $\begin{array}{l}\text { SD improved on } \\
\text { trained items. } \\
\text { Maintained at } 1 \\
\text { month. some } \\
\text { generalisation }\end{array}$ \\
\hline $\begin{array}{l}\text { Dressel et al. } \\
(2010)\end{array}$ & $\begin{array}{l}1 \text { case, pre-post- } \\
\text { follow up }\end{array}$ & $\begin{array}{l}1 \text { person with } \\
\text { SD }\end{array}$ & $\begin{array}{l}\text { Phonological and } \\
\text { semantic cueing }\end{array}$ & Investigate use of treatment & $\begin{array}{l}\text { Improved with both } \\
\text { techniques at } 2\end{array}$ \\
\hline
\end{tabular}




\section{Fick et al. (2014) Case report}

1 person with FTD

Frattali (2004)

Case study, prepost- follow up

1 person with Errorless learning FTD

Izzo, DiLorenzo, Case study and Roth (1986)

Jefferies, Bott, Ehsan, and Ralph (2011)

Jokel and

Anderson (2012)

Jokel et al. (2006)

Case study, pre-postfollow up.

\section{groups}

7 cases, pre-post$$
\text { follow up. }
$$$$
\mathrm{SD}
$$

1 case, pre-post-
follow up

Jokel, Rochon and Anderson (2010)
1 person with SD

\section{1 person with Therapeutic} Progressive rehabilitation Supranuclear techniques. Palsy

1 person with List recall and errorless $\mathrm{SD}, 8$ controls

7 people with SD

1 person with SD learning

Errorless, errorful, active and passive learning of naming and comprehension of treated words

Home treatment programme (practising words of objects)

Computer delivered errorless learning
Behavioural intervention

Describe intervention for pacing + vocally disruptive behaviour

Explore effectiveness

Discuss the rehabilitation problems and management of the person.

Explore whether and how can learn phonological information

\section{Examine different} combinations of training techniques

\section{Explore a treatment} programme. Designed jointly with participant.

Explore effectiveness + feasibility months but gains lost over time

Vocally disruptive behaviour + pacing reduced

Improved on trained, no generalisation, gains lost at 3 months Improvement in dysphagia and visual scanning.

Phonological learning improved
All training resulted in improvement.

Errorless training was better maintained

Better on words with some retained semantic knowledge. Practice delayed progression of loss.

Good learning and 3 month retention 
Newhart et al.

(2009)

2 cases, pre-post $(1$ LPA, 1 SD)

O'Connor et al. Case study (2016)

Robinson et al. (2009)

Savage et al

Savage, Piguet, and Hodges

Savage et al. (2015)

with matched

controls, pre- post-

follow up

6 cases, pre-post

Pre- and postintervention comparison
1 person with

behavioural,

semantic

4 people with

Case series of single- 9 people with

subject experimental SD design
1 person with $\mathrm{SD}, 1$ person with

logopaenic

progressive

aphasia

FTD-

1 person with

FTD-

2 people with Errorless learning and $\mathrm{SD}, 2$ training SD

Cue hierarchy treatment for naming objects

OT

\section{Word retraining} (repetitive practice of word-picture pairing)

5 people with Online word training SD program

(n)

\author{
Computer delivered \\ rehearsal (individually \\ tailored) of 75-100 \\ words
}

Compare treatment across LPA and SD on lexical processing assessment

\section{Describe intervention and assess feasibility}

Explore training effectiveness (object naming, definition and use)

\section{Evaluate the success of training}

Examine whether gains in
training generalise from picture
naming to everyday settings

Examine independent and assisted maintenance of object words
SD better with trained words but limited maintenance

Engagement in more activities,

improvements in behaviour, reduced caregiver distress

Improved naming, definitions and object use

\section{More practice time} improved maintenance (not much maintenance).

All 5 improved naming the trained pictures; 4 out of 5 improved on video description task

$80 \%$ trained words retained at six months with independent or continuous revision 
Snowden and

Neary (2002)

Two case studies

Snowden et al. (2012)

Case study, pre-post follow up

1 person with

Suárez-González Case study. et al. (2015)

\section{Compared standard} and conceptual enrichment training

\section{Huntington's disease (HD) - 7 studies}

Ciancarelli,

Tozzi, and

Repeated measures

Carolei (2013)

Frich et al. (2014) Qualitative interview (patients and caregivers) or focus groups (professionals) postintervention

Klasner and

Yorkston (2001)
Case study
2 people with SD

Repetition (some elements of errorless learning) of object names PPA

Speech and language therapy

1 person with Conceptual enrichment SD training

\section{Case description}

\section{4 people Inpatient} with HD

multifunctional neuro rehabilitation

9 carers, 11 people with $\mathrm{HD}, 15$ healthcare professionals

Group-based multidisciplinary residential rehabilitation (inc.

training of cognitive

function, assistive devices; individual counselling)

1 person with SALT (linguistic and HD cognitive strategies

taught to aid

communicative

participation)
Examine the impact of residual word/ object knowledge and contextual information on relearning

See whether generalisation improved if personalised semantic memories recruited

Partial semantic knowledge and experiential contextual information aided relearning

Improvement at 12 months but gains lost at 2 years

Better naming and generalisation with conceptual enrichment training

Explore intervention effectiveness

Improvements lost at 3 month follow-up

Assess feasibility (opinions of patients, caregivers, and professionals)

Describe the use of linguistic and cognitive supplementation strategies

Patients and caregivers emphasised positive mental, physical, and social outcomes, professionals indicated intervention was feasible

Improved frequency and satisfaction with communication and ADL completion 
Mattern and Kane Case study

(2007)

Piira et al. (2013) Repeated measures ( 3 admissions of 3 weeks over 1 year)

Thompson et al. Between groups (2013)

Zinzi et al. (2007) Repeated measures (3 week intensive, 3 times a year)

\section{Motor Neuron disease (MND) - $\mathbf{5}$ studies}

Cleary (2008)

Case study

1 person with MND

20 people with HD

40 people

with HD

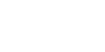

Kaiser et al.

(2001)

37 people with HD $\begin{array}{ll}1 \text { person with } & \text { Occupational therapy- } \\ \text { HD } & \text { activity programme }\end{array}$

Inpatient rehabilitation (physical exercise, social activities, group sessions)

MDT OT rehabilitation

Multicomponent-

inpatient rehabilitation

Behavioural - to decrease risk of pneumonia (e.g. instruction in good oral hygiene)

2 people with OT- computer device MND training
Pilot the programme

Explore effectiveness

Replicate Zinzi et al 2007 study

Explore effectiveness

Describe the case

Improved sense of purpose and developed friendships

Improved gait, balance, physical QOL, anxiety and depression. No deterioration in cognition

Improvement in mobility, body strength, written errors and fat composition. Minor improvement $\operatorname{cog}+$ depression

Improved motor performance, ADL performance and depression

\section{Describe intervention}

Improved nutrition, energy, satisfaction, reduced distress and improved caregiver QOL

Evaluate the training technique (locked-in patients learned to use an EEG-based communication device)
Learnt to control cortical potentials without continuous feedback 


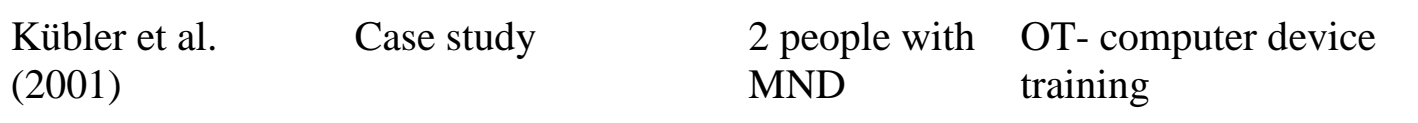

Neumann,

Case study

1 person with

Kübler, Kaiser,

Hinterberger, and

Birbaumer (2003)

Traynor et al.

(2003)

Between groups-

retrospective

analysis

MND

344 people with MND

\section{Parkinsonian Disorders (PDs) - 8 studies}

Clarke et al.

Multi-centre RCT

(PD REHAB Trial)

762 people
with PD

training (brain-

computer

communication)

MDT team care

(neurologists, specialist nurses, occupational,

speech therapists,

pulmonologist,

nutritionist,

psychologist, social

worker)

People with limitations

in ADL were randomised to

physiotherapy and

occupational therapy or

no therapy

Disbrow et al.

Between groups, 10-

(2012) day training
30 people

with PD, 21

controls
Computerised cognitive rehabilitation (designed to improve motorrelated exec function)
Describe and evaluate training (locked-in patients learned to use an EEG-based

communication device)

To describe how a participant controlled EEG potentials

Able to learn to control amplitude of slow cortical potentials

Used mental strategies to shift EEG potentials

Evaluate outcomes on survival

MDT care increased survival time for bulbar onset patients (compared with general neurology clinic control)

Evaluate efficacy

There were no significant improvements in the activities of daily living measure or the Parkinson Disease self-report measure in the therapy group.

Improvement in motor initiation and some generalisation to cognitive switching. 


Gil-Ruiz et al.
(2013)
Giovannetti,
Seligman,
Britnell, Brennan,
and Libon (2015)

Jain et al. (2004)

Pilot RCT

Article describes the

Meek et al.

(2010)

Between-groups

20 people with PDD, 20

people with

$\mathrm{AD}, 20$

people with

PD

17 people

Individual OT

with MSA

19 people

with PD and recording the

intervention

Pretzer-Aboff,
Galik, and

Resnick (2011)

\section{Repeated measures}

21 people with PD

intervention focused care

adaptation for

reflection)

goals/ improve
Individual function

Case description management of the

'mirror sign' (inability

to recognise one's

Goal cues (remind task Assess feasibility

performance on

everyday tasks)

\section{Individual OT to}

optimise independence

Identify feasibility and preliminary impact

Detail the intervention

Improvement on Trail Making B-A

Improved DSM

symptoms

AD patients showed a significantly greater response to goal cues as compared with PD + dementia, the goal cues facilitated task completion, but did not promote error correction

Improved ADL

functioning and health related QOL

Mean number of visits 5.7

Found to be feasible and acceptable,

informed larger phase 3 trial (PD REHAB)

Improved time spent exercising, disability, impairment, outcome 


\section{Sturkenboom et Process analysis}

al. (2013)

\section{Multiple sclerosis (MS) - 21 studies}

Allen, Longmore, Repeated measuresand Goldstein case study (1995)

Allen, Goldstein, Single group preHeyman, and and post-training

Rondinelli (1998) comparisons

Asano, Preissner, Duffy, Meixell, and Finlayson (2015)

Birnboim and Miller (2004)

from an RCT

(Finlayson et al.,

2005) appears to

report only the goal-

setting group

Single group pre-

and post-training

43 people
with $\mathrm{PD}, 43$
carers, 7
healthcare
practitioners

1 person with
MS

Individual OT

Evaluate feasibility

Cognitive training

(teaching mnemonic

strategies to increase

list learning

+ recall of names of

faces)

10 people

with MS

Computer-assisted

teaching of imagery-

based mnemonic

strategies

\section{1 people \\ Goal-setting}

with MS

comparisons and 2

case studies

Describe effect

Evaluate feasibility

10 people with MS with metacognitive

therapeutic approach
Explore efficacy expectations for exercise and QOL

Feasibility

demonstrated but

response rate $23 \%$

Improved list learning, quicker name learning

Participants quickly learned the strategies but methods showed no significant effects on recall

Describe goals set and evaluate the extent to which participants keep goals over time

Around 50\% of goals are achieved, the most common being IADL's and shortterm goals
An overall improvement 
for executive function

deficits

Carr et al. (2014) Pilot RCT

48 people

with MS

Cognitive rehabilitation

Assess feasibility

Chiaravalloti et

RCT (double-blind, placebo)

RCT (double-blind, placebo)

Wylie, Leavitt, and Deluca

(2012)

Eyssen et al. Cluster RCT (2013)

Fink et al. (2010) Between groups
86 people with MS

\author{
40 people Cognitive training - \\ with MS-RR attention/ exec function \\ (RehaCom software)
}

Evaluate efficacy

\author{
Cognitive rehabilitation Treat learning impairment \\ (modified Story \\ Memory Technique, \\ mSMT)
}
16 people Cognitive rehabilitation Investigate if the cognitive with MS intervention created neural changes

25 people with MS, 35 controls

269 people with MS
Probe the programme

Assess efficacy

Client-centred
occupational therapy
Improved mood. No effect of memory programme on memory outcome measures

Significantly improved learning and memory compared to placebo group Increased activation and improved list learning

Improved autobiographical memory performance

No difference in primary outcome, negative findings in secondary outcomes, and positive findings in process outcomes Improvement in aspects of executive function, improved verbal learning 


\begin{tabular}{|c|c|c|c|c|}
\hline Gentry (2008) & Repeated measures & $\begin{array}{l}21 \text { people } \\
\text { with MS }\end{array}$ & $\begin{array}{l}\text { Assistive Device } \\
\text { training (personal } \\
\text { digital assistants, e.g. } \\
\text { calendar, alarms) }\end{array}$ & $\begin{array}{l}\text { Evaluate impact on functional } \\
\text { performance }\end{array}$ \\
\hline $\begin{array}{l}\text { Goverover et al. } \\
(2008)\end{array}$ & Between groups & $\begin{array}{l}20 \text { people } \\
\text { with MS, } 18 \\
\text { controls }\end{array}$ & $\begin{array}{l}\text { Cognitive rehabilitation } \\
\text { (self-generation to } \\
\text { improve learning/ } \\
\text { memory of meal } \\
\text { preparation and } \\
\text { managing finances). }\end{array}$ & Examine strategy utility \\
\hline $\begin{array}{l}\text { Klaren, Hubbard, } \\
\text { and Motl (2014) }\end{array}$ & $\begin{array}{l}\text { Pilot RCT, pre- and } \\
\text { post- trial } \\
\text { questionnaire }\end{array}$ & $\begin{array}{l}70 \text { people } \\
\text { with MS }\end{array}$ & $\begin{array}{l}\text { Behavioural } \\
\text { intervention (to reduce } \\
\text { sedentary behaviour) }\end{array}$ & Examine efficacy \\
\hline $\begin{array}{l}\text { Lexell, Flansbjer, } \\
\text { and Lexell (2014) }\end{array}$ & $\begin{array}{l}\text { Retrospective study } \\
\text { with a pre-post } \\
\text { design }\end{array}$ & $\begin{array}{l}43 \text { people } \\
\text { with MS }\end{array}$ & $\begin{array}{l}\text { Individualised, goal- } \\
\text { oriented } \\
\text { interdisciplinary } \\
\text { rehabilitation }\end{array}$ & $\begin{array}{l}\text { Assess self-perceived } \\
\text { performance and satisfaction } \\
\text { with performance of daily } \\
\text { activities }\end{array}$ \\
\hline $\begin{array}{l}\text { Lincoln et al. } \\
(2002)\end{array}$ & RCT (single blind) & $\begin{array}{l}240 \text { people } \\
\text { with MS }\end{array}$ & $\begin{array}{l}\text { Cognitive rehabilitation } \\
\text { (cognitive deficits } \\
\text { identified with battery, } \\
\text { then given tailored } \\
\text { intervention. E.g. } \\
\text { training in use of } \\
\text { diaries) }\end{array}$ & $\begin{array}{l}\text { Evaluate benefit cognitive } \\
\text { assessment and intervention }\end{array}$ \\
\hline $\begin{array}{l}\text { Lincoln et al. } \\
(2003)\end{array}$ & $\begin{array}{l}\text { Secondary analysis } \\
\text { of RCT treatment } \\
\text { group (Lincoln et al., } \\
\text { 2002) }\end{array}$ & $\begin{array}{l}29 \text { people } \\
\text { with MS }\end{array}$ & $\begin{array}{l}\text { Cognitive rehabilitation } \\
\text { (individualised) }\end{array}$ & Evaluate rehabilitation \\
\hline
\end{tabular}

Improved functional performance and satisfaction

Self-generation improved learning and memory recall

Sitting time significantly reduced in the intervention group

Self-perceived performance and satisfaction higher after rehabilitation program

No significant outcomes on mood, quality of life, subjective cognitive impairment, independence

Only a quarter of participants benefitted 


\begin{tabular}{|c|c|c|c|c|c|}
\hline $\begin{array}{l}\text { Mäntynen et al. } \\
\text { (2014) }\end{array}$ & $\mathrm{RCT}$ & $\begin{array}{l}102 \text { people } \\
\text { with MS-RR } \\
\text { and } \\
\text { subjective } \\
\text { and objective } \\
\text { attentional } \\
\text { deficits }\end{array}$ & $\begin{array}{l}\text { Cognitive rehabilitation } \\
\text { (inc. computer WM } \\
\text { training, } \\
\text { psychoeducation, } \\
\text { strategy learning, psych } \\
\text { support) }\end{array}$ & Evaluate efficacy & $\begin{array}{l}\text { No improvement in } \\
\text { cognitive performance } \\
\text { (processing speed, } \\
\text { SDMT). Patients } \\
\text { perceived reduction in } \\
\text { cognitive deficits. }\end{array}$ \\
\hline $\begin{array}{l}\text { Rosti-Otajärvi, } \\
\text { Mäntynen, } \\
\text { Koivisto, } \\
\text { Huhtala, and } \\
\text { Hämäläinen } \\
\text { (2013) }\end{array}$ & $\begin{array}{l}\text { Secondary analysis } \\
\text { of RCT (Mäntynen } \\
\text { et al., 2014) }\end{array}$ & $\begin{array}{l}98 \text { people } \\
\text { with MS-RR }\end{array}$ & $\begin{array}{l}\text { Neuropsychological } \\
\text { rehabilitation (attention } \\
\text { retraining, teaching } \\
\text { compensatory } \\
\text { strategies, psych } \\
\text { support, homework). }\end{array}$ & $\begin{array}{l}\text { Evaluate factors related to } \\
\text { outcome. }\end{array}$ & $\begin{array}{l}\text { More benefit for those } v \\
\text { more severe attentional } \\
\text { deficits (+male) }\end{array}$ \\
\hline $\begin{array}{l}\text { Salminen, } \\
\text { Kanelisto, and } \\
\text { Karhula (2014) }\end{array}$ & $\begin{array}{l}\text { Qualitative analysis } \\
\text { of focus group data }\end{array}$ & $\begin{array}{l}68 \text { people } \\
\text { with MS }\end{array}$ & $\begin{array}{l}\text { Multi-professional } \\
\text { group-based out-patient } \\
\text { rehabilitation programs }\end{array}$ & $\begin{array}{l}\text { Identify which components of } \\
\text { rehabilitation are seen as } \\
\text { helpful by people with MS }\end{array}$ & $\begin{array}{l}\text { Diverse range of } \\
\text { components identified }\end{array}$ \\
\hline $\begin{array}{l}\text { Shatil et al. } \\
(2010)\end{array}$ & $\begin{array}{l}\text { Between groups } \\
\text { (unprompted, home- } \\
\text { based, computerised } \\
\text { training) }\end{array}$ & $\begin{array}{l}107 \text { people } \\
\text { with MS }\end{array}$ & $\begin{array}{l}\text { Cognitive training } \\
\text { (CogniFit Personal } \\
\text { Coach) }\end{array}$ & $\begin{array}{l}\text { Examine impact on cognitive } \\
\text { performance }\end{array}$ & $\begin{array}{l}\text { Improved general } \\
\text { memory, visual } \\
\text { memory, verbal- } \\
\text { auditory working } \\
\text { memory, LTM } \\
\text { retrieval, naming, } \\
\text { recall and processing } \\
\text { speed }\end{array}$ \\
\hline $\begin{array}{l}\text { Stuifbergen et al. } \\
\text { (2012) }\end{array}$ & $\begin{array}{l}\text { RCT (single blind, } \\
\text { waiting list control) }\end{array}$ & $\begin{array}{l}61 \text { people } \\
\text { with MS }\end{array}$ & $\begin{array}{l}\text { Cognitive rehabilitation } \\
\text { (Memory, Attention } \\
\text { and Problem Solving }\end{array}$ & Refine and test the intervention & $\begin{array}{l}\text { Improved self-efficacy } \\
\text { and frequency of } \\
\text { compensatory strategy } \\
\text { use }\end{array}$ \\
\hline
\end{tabular}


Skills for Persons with

MS, MAPSS).

(b) Psychological therapies for adjustment and mood

\begin{tabular}{|c|c|c|c|c|c|}
\hline Authors \& Date & Design & Sample & Intervention & Aims & Key findings \\
\hline \multicolumn{6}{|c|}{ Fronto-temporal dementia (FTD) - 1 study } \\
\hline $\begin{array}{l}\text { Yokota et al. } \\
\text { (2006) }\end{array}$ & $\begin{array}{l}\text { Pre- and post- } \\
\text { intervention } \\
\text { comparisons }\end{array}$ & $\begin{array}{l}8 \text { people } \\
\text { with FTD }\end{array}$ & Group-Home Care & $\begin{array}{l}\text { Evaluate impact of homelike } \\
\text { physical and social } \\
\text { environment in a care home. }\end{array}$ & $\begin{array}{l}\text { Beneficial effects on } \\
\text { behavioral and } \\
\text { psychological } \\
\text { symptoms of dementia, } \\
\text { and psychotropic drug }\end{array}$ \\
\hline \multicolumn{6}{|c|}{ Huntington's disease (HD) - 2 studies } \\
\hline Silver (2003) & $\begin{array}{l}\text { Repeated measures, } \\
\text { case study }\end{array}$ & $\begin{array}{l}1 \text { person } \\
\text { with HD }\end{array}$ & CBT- individual & $\begin{array}{l}\text { Describe key features of } \\
\text { therapy and outcome }\end{array}$ & $\begin{array}{l}\text { Improved anxiety and } \\
\text { depression ratings }\end{array}$ \\
\hline $\begin{array}{l}\text { Sullivan et al. } \\
\text { (2001) }\end{array}$ & Case studies & $\begin{array}{l}6 \text { people } \\
\text { with HD }\end{array}$ & $\begin{array}{l}\text { Remotivation (group) } \\
\text { therapy }\end{array}$ & Present case studies & Positive gains reported \\
\hline \multicolumn{6}{|c|}{ Motor neuron disease (MND) - 3 studies } \\
\hline $\begin{array}{l}\text { Averill et al. } \\
\text { (2013) }\end{array}$ & $\mathrm{RCT}$ & $\begin{array}{l}48 \text { people } \\
\text { with MND }\end{array}$ & Psychotherapy & $\begin{array}{l}\text { Examine impact on } \\
\text { psychological well-being }\end{array}$ & $\begin{array}{l}\text { Improved psychological } \\
\text { well-being but not } \\
\text { maintained at six } \\
\text { months }\end{array}$ \\
\hline $\begin{array}{l}\text { Bentley et al. } \\
\text { (2014) }\end{array}$ & Repeated measures & $\begin{array}{l}29 \text { people } \\
\text { with MND }\end{array}$ & $\begin{array}{l}\text { Psychotherapy (dignity } \\
\text { therapy) }\end{array}$ & $\begin{array}{l}\text { Assess feasibility, acceptance } \\
\text { and potential effectiveness }\end{array}$ & No significant outcomes \\
\hline
\end{tabular}


Pérez and Dapueto Case study (2014)

\section{Parkinsonian Disorders (PDs) - 5 studies}

Dobkin et al. (2007)

Pilot repeated

measures

15 people with PD

80 people with PD

Dobkin et al. (2014)

Additional analysis

Fitzpatrick,

Simpson, and of RCT

80 people with PD

12 people with PD

structured

Smith $(2010)$

interview)

Jiménez-Murcia et Between groups al. (2012)

60 people

with PD

$$
\text { analysis (pilot) }
$$

\section{Multiple sclerosis (MS) - 17 studies}

Askey-Jones,

Repeated measures

David, Silber,

(not blinded)

49 people with MS

Shaw, and Chalder

(2013)

$\begin{array}{ll}\begin{array}{l}\text { Computer assisted } \\ \text { (augmentative- }\end{array} & \begin{array}{l}\text { Describe how therapy was } \\ \text { provided }\end{array}\end{array}$

alternative

communication

technology)

Psychotherapy (based

on CBT)

\section{Individual CBT for}

depression in PD

Individual CBT for

depression in PD

CBT

Mindfulness based

cognitive therapy

(MCBT)

Individual CBT for

pathological gambling

in PD

CBT (individual) for common mental disorders in MS

Feasibility testing

First trial of CBT in PD outcomes

Explore experiences of

MCBT (8 week course)

\section{Examine effectiveness}

Positive outcomes reported (improved communication with computer device, improved self-esteem, lower distress)

Describe neuropsychological

Positive experiences/ gains reported

Characterise therapy response

No differences in response between pathological gamblers with or without PD

Reduced depression and anxiety but not maintained 
Beckner, Howard, Vella, and Mohr (2010)

Boeschoten et al. (2012)

Bombardier et al. (2013)

Burns, Siddique, Fokuo, and Mohr (2010)

Clancy, Drerup, and Sullivan

Dennison, MossMorris, Yardley,

Kirby, and

Chalder (2013)

Graziano,

Calandri, Borghi, and Bonino (2014)
127 people CBT (telephone) for

with MS 2005)

44 people with MS

CBT (computerised) for

\section{2 people} with MS

Secondary analysis of RCT (Mohr et al. 2005)

Single group pre-

11 people

and post-

ntervention

evaluation

Qualitative

30 people

with MS with MS

82 people with MS

Telephone-based

physical activity

counselling for major

depression in MS

102 people CBT (telephone) for depression

CBT

CBT (mixed format) for

Gain insight into participant experience

Evaluate effectiveness

CBT (group) for reducing depression and improving quality of life

Examine effectiveness

Effects of comorbid anxiety on outcome

Evaluate efficacy depression in MS depressive systems in MS adjustment to MS

Examine whether social

support is a mediator

Examine feasibility and to examine outcome
Patients with higher social support responded better to

\section{CBT}

Improved depression, problem solving skills and anxiety

Improved depression

Comorbid fear reduced maintenance and comorbid GAD increased anxiety symptoms

Improvements in insomnia, fatigue, and depression, although symptoms persisted

Positive outcomes reported

Improved QOL and (in men) psychological well being 
$\begin{array}{ll}\text { Mohr, Classen, } & \text { Clinical trial, } \\ \text { and Barrera (2004) } & \text { between groups }\end{array}$

Mohr, Hart, and

Goldberg (2003)

Mohr et al. (2005) RCT +12 month follow-up

Mohr, Hart, and Vella (2007)

Nordin and Rorsman (2012)

Pre- and postintervention assessment of RCT (Mohr et al., 2005)

Pilot RCT.
63 people CBT, supportive with MS-RR expressive group psychotherapy, or sertraline

Additional analysis

21 people with MS with MS-RR psychotherapy, or sertraline

127 people with MS

127 people with MS focused therapy (telephone) for depression in MS focused therapy (telephone) for depression in MS

Acceptance and
Examined the effects of treatment for depression on social support

60 people Individual CBT, group

CBT (telephone) and supportive emotion-

CBT (telephone) and supportive emotioncommitment therapy (group)/ relaxation therapy (group) for MS with depression/ anxiety
Examine the effects of treatment for depression on fatigue

Evaluate efficacy for attention and nonspecific therapy

effects

Evaluate effects on disability and fatigue

Evaluate effectiveness
All treatment

interventions alleviated depression and increased perceived social support, utilised social support, and satisfaction with support.

All treatment interventions reduced fatigue severity, which was associated with fewer symptoms of depression.

Significant improvement in depression measures and positive affect

CBT superior in reducing disability and fatigue, depression

At 3 month follow up, relaxation training group had improvement in anxiety, acceptance and commitment therapy group showed 


\section{Rigby, Thornton,} and Young (2008)
RCT assessing outcomes at five points over a one year follow up
138 people with MS

CBT (group), educational material (booklet), or educational material (booklet) + nonstructured social discussion

\section{5 people} with MS and postassessment +3

follow up Bianchi (2010)

\section{Hickling, and}

\section{Acceptance and commitment therapy \\ Investigate efficacy}

Document mood, selfefficacy, and resiliency following group CBT and to examine whether benefits were greater than those derived from provision of education or group social interaction.

\section{Thomas et al.}

(2013)

Multicentre RCT (not blinded)

van Kessel et al. (2008)
RCT

T

\section{6 people CBT (group) for fatigue Effectiveness with MS management}

72 people with MS improvement in selfrated acceptance

CBT improved self-effica and resiliency, and reduce anxiety, in comparison wi educational booklet intervention (but no significant difference). Al no difference between educational book and educational book + social discussion

Significant improvement in depression, thought suppression, impact of pain on behaviour, and QOL, but no change in the experience of physical symptoms and mindfulness practice.

Improved fatigue, severity and selfefficacy

CBT group reported significant reductions in fatigue, but there was no difference in stress, mood, or fatigue related impairment. 
(c) Education and self-management

\begin{tabular}{|c|c|c|c|c|c|}
\hline Authors \& Date & Design & Sample & Intervention & Aims & Key findings \\
\hline \multicolumn{6}{|c|}{ Motor neuron disease (MND) - 2 studies } \\
\hline $\begin{array}{l}\text { Kasarkis et al. } \\
\text { (1997) }\end{array}$ & Survey & $\begin{array}{l}\text { Approximately } 100- \\
130 \text { people with MND } \\
\text { attended at least one } \\
\text { session }\end{array}$ & $\begin{array}{l}\text { Informational support } \\
\text { group using interactive } \\
\text { video format }\end{array}$ & $\begin{array}{l}\text { Describe the } \\
\text { approach }\end{array}$ & $\begin{array}{l}\text { High degree of user } \\
\text { satisfaction and } \\
\text { proficiency in using } \\
\text { interactive video }\end{array}$ \\
\hline Regan et al. (2008) & Survey & 15 people with MND & $\begin{array}{l}\text { Education and support } \\
\text { group }\end{array}$ & $\begin{array}{l}\text { Six month pilot of } \\
\text { the programme }\end{array}$ & Positive feedback \\
\hline \multicolumn{6}{|c|}{ Parkinsonian Disorders (PDs) - 4 studies } \\
\hline $\begin{array}{l}\text { A'Campo, } \\
\text { Spliethoff- } \\
\text { Kamminga, Macht, } \\
\text { Roos, and } \\
\text { Consortium (2010) }\end{array}$ & $\begin{array}{l}\text { Repeated measures } \\
\text { \& feedback }\end{array}$ & $\begin{array}{l}64 \text { people with PD, } 46 \\
\text { carers }\end{array}$ & PEPP patient education & $\begin{array}{l}\text { Evaluate caregiver } \\
\text { impact }\end{array}$ & $\begin{array}{l}\text { Improved burden (PD } \\
\& \text { caregiver) }\end{array}$ \\
\hline $\begin{array}{l}\text { A'Campo, } \\
\text { Spliethoff- } \\
\text { Kamminga, and } \\
\text { Roos (2011) }\end{array}$ & $\begin{array}{l}\text { Secondary analysis } \\
\text { of A'Campo et al. } \\
\text { (2010), standardised } \\
\text { patient education } \\
\text { programme for } \\
\text { patients with } \\
\text { Parkinson's disease } \\
\text { and their carers }\end{array}$ & $\begin{array}{l}64 \text { people with } \mathrm{PD}, 46 \\
\text { carers }\end{array}$ & $\begin{array}{l}\text { PEPP group patient } \\
\text { education }\end{array}$ & $\begin{array}{l}\text { Identify treatment } \\
\text { effect modifiers }\end{array}$ & $\begin{array}{l}\text { No modifiers of PD } \\
\text { outcomes } \\
\text { Potential predictor of } \\
\text { treatment benefit - } \\
\text { caregiver having } \\
\text { higher cog function }\end{array}$ \\
\hline $\begin{array}{l}\text { Dorsey et al. } \\
(2010)\end{array}$ & Postal survey & 726 people with PD & Support groups (patient) & $\begin{array}{l}\text { Assess patient } \\
\text { satisfaction with } \\
\text { medical care and } \\
\text { use of support } \\
\text { groups }\end{array}$ & $\begin{array}{l}61 \% \text { reported } \\
\text { attending support } \\
\text { group, } 49 \% \text { satisfied }\end{array}$ \\
\hline
\end{tabular}


Mulligan et al.

(2011)

Single group post-

8 people with $\mathrm{PD}$ intervention

qualitative interview

\section{Multiple sclerosis (MS) - 36 studies}

Barlow, Turner, RCT

Edwards, and

Gilchrist (2009)

Barlow, Edwards, and Turner (2009)

Qualitative

secondary analysis

of Barlow et al.

2009

Bombardier et al.

(2008)

RCT (1 phone

interview then 5

telephone

counselling

sessions)

Cecil (2014)

Dlugonski, Motl, and McAuley

(2011)

Dlugonski, Motl,

Case study

description

Repeated measures

Mohr, and

Sandroff (2012)
216 people with MS

30 people with MS

8 people with MS-

Progressive

21 people with MSRR

45 people with MSRR

Self-management

intervention

Assess feasibility

Improved knowledge and new strategies for living with PD and psychosocial benefits of meetings

Self-management

(chronic disease selfmanagement course, layled)

Self-management

Telephone counselling for health promotion

Support group (telephone) for homebound patients (MS)

Self-management (internet) - increase physical activity

Self-management (internet) - increase physical activity
Determine

effectiveness

Explore

experiences and

value

\section{Determine \\ effectiveness}

Consider first eight years of the group

Examine efficacy using objective and self-report measures

Evaluate efficacy sed activity and self-report measures

Improved self-

efficacy and physical health status

Benefits perceived

Improved health promotion behaviour, fatigue impact, mental health related QOL and self-reported physical activity

Positive feedback Increased physical activity 
Ehde et al. (2015) Single centre RCT +163 people with MS 6 and 12 month follow up

Feys et al. (2013)

Uncontrolled interventional study with

repeated measures

Finlayson, Garcia, Qualitative and Preissner (2008)

Finlayson,

Preissner, Cho, and

Plow (2011)

Finlayson (2005)

Pilot repeated measures

Ghahari, Packer, and Passmore

Single group preand post-training (2009) comparisons

Knoop, van Kessel, Secondary analysis and Moss-Morris of RCT (van Kessel (2012) et al. 2008)
Self-management intervention (telephone delivered)

42 people with MS

Education day with theoretical and practical sessions to increase physical activity level

28 people with MS, 3 Energy conservation healthcare practitioners

(teleconference delivered) education program

190 people with MS

Energy conservation

(teleconference-delivered fatigue management program)

190 people with MS

Energy conservation (group, teleconference)

9 people with MS and 2 people with PD (no separate analysis)

70 people with MS

CBT- face to face and telephone for fatigue management
Evaluate efficacy Significantly improved symptoms of fatigue, pain, depression, selfefficacy, activation, health related QOL, resilience, and affect.

Evaluate effects

Enhanced physical

activity behaviour in persons without perceived disability

Positive feedback but also limitations highlighted

Explore

Improved fatigue impact and aspects of HRQOL

efficacy

Explore efficacy

Reduced fatigue impact and severity, better bodily pain and general health

Develop program Decreased fatigue

and evaluate effectiveness

Assess mediators

Changing negative representations of fatigue crucial. CBT 


\begin{tabular}{|c|c|}
\hline $\begin{array}{l}\text { Mathiowetz, } \\
\text { Matuska, and } \\
\text { Murphy (2001) }\end{array}$ & $\begin{array}{l}\text { Repeated measures } \\
\mathrm{AB} \text { design }\end{array}$ \\
\hline $\begin{array}{l}\text { Mathiowetz, } \\
\text { Finlayson, } \\
\text { Matuska, Chen, } \\
\text { and Luo (2005) }\end{array}$ & $\begin{array}{l}\text { RCT with } \\
\text { immediate - delaye } \\
\text { control group cross } \\
\text { over design }\end{array}$ \\
\hline $\begin{array}{l}\text { Mathiowetz, } \\
\text { Matuska, } \\
\text { Finlayson, Luo, } \\
\text { and Chen (2007) }\end{array}$ & $\begin{array}{l}\text { Follow-up } \\
\text { secondary data } \\
\text { analysis (see } \\
\text { Mathiowetz et al. } \\
\text { 2005) }\end{array}$ \\
\hline
\end{tabular}

Moss-Morris et al. Pilot RCT

(2012)

Motl and

Dlugonski (2011)

Repeated measures (interrupted time series)

Motl, Dlugonski, $\quad$ Pilot RCT Wójcicki,

\section{4 people with MS}

169 people with MS

169 people with MS

Energy conservation course on fatigue impact, self-efficacy and QOL

Energy conservation course for people with MS, some with mild cognitive impairment

\section{Energy conservation} course

206 people with MS

Self-management prompts (web-based, participant generated)

40 people with MS

Self-management (internet-based CBT selfmanagement for MS, focus on fatigue)

18 people with MS-

Self-management physical activity

54 people with MSRR RR

Self-management (internet) - focus on (internet)-increase

Evaluate

effectiveness

Assess the short-

term efficacy and effectiveness

Report of 1-year follow-up analysis

Investigate effectiveness \& feasibility

Feasibility

Examine better than relaxation training (RT)

Improved fatigue impact, self-efficacy and aspects of QOL

Decreased fatigue, increased self-efficacy and some aspects of quality of life

Decreased fatigue and improved quality of life maintained up to 1 year post-intervention

No group differences in favour of selfmanagement prompts

Reduction in fatigue severity and impact. Improved anxiety and depression and increased QALYs effectiveness

Increased selfreported and objectively measured physical activity (small) physical activity
Examine

effectiveness

Increased self-

reported physical activity levels 
McAuley, and

Mohr (2011)

Motl, Dlugonski,

Pilutti, and Klaren

(2015)

Mulligan,

Treharne, Hale,

and Smith (2013)

Qualitative analysis

of the feasibility

trial data

Navipour et al.

(2006)

Ng et al. (2013)
RCT, pre- and postintervention

assessment

(Secondary analysis)

\section{Pre- and post- intervention \\ comparisons}

Pre- and post-
27 people with MS

Combined self-help and professional help "Blue Prescription" to minimize physical and social barriers to participation intervention comparisons and follow-up assessment

Short-term self-managed graded exercise programme for various MS symptoms

129 people with MS

Wellness program of psychological and physiological evaluations, lectures and workshops
Behavioural intervention

with goal-setting

component to increase

physical activity
Examine efficacy

Participants in the behavioural intervention group had significantly higher physical activity levels than controls. The efficacy of the intervention was moderated by MS type, disability status, and weight status.
Establish content and resources

required for delivery of the approach

Increased

participation

in community-based

physical activity

physical activity of

their choice

Evaluates effects

Improved self-esteem and fatigue

Determine efficacy Improved selfefficacy and selfperceived

health related outcomes, but no increase in physical activity 
O'Hara, Cadbury,

De Souza, and Ide (2002)

Pilutti, Dlugonski,

Sandroff, Klaren,

and Motl (2014)

Plow, Bethoux,

McDaniel,

McGlynn, and

Marcus (2014)

Plow, Bethoux,

Mai, and Marcus

(2014)

Rietberg, van

Wegen, Eyssen, and Kwakkel

Sandroff et al. (2014)
169 people with MS

Self-management (group/ Test efficacy individual)

\section{RCT}

Secondary analysis of data from RCT (see Sandroff et al., 2014)

Pilot RCT randomly allocated two-group repeated measures design, delayed-treatment contact group was control

\section{Additional}

secondary analysis of Plow et al 2014 (above)

RCT, pre- and posttrial assessment +24 week follow up

30 people with MS-

RR

Patient education

(customised pamphlets)

management

(internet) - physical activity

30 people with MS-

RR

Patient education

(customised pamphlets)

\section{8 people with MS}

Multidisciplinary rehabilitation (received either physical therapy, OT, social work, or any combination of these)

Secondary analysis of RCT (Motl et al. 2011)
82 people with MSRR
Self-management (internet) - increase
Examine

effectiveness on

secondary

outcomes

\section{Explore}

effectiveness

Improved mental

health, fatigue and perceived need for assistance

Improved fatigue severity and impact, anxiety and depression and physical activity level

Increased stage of change, social support, use of behaviour strategies

\section{Additional analysis Improved physical activity, symptom severity, walking}

\section{Assess efficacy No significant} differences at 12 or 24 weeks follow up for fatigue, functional independence, impact on QOL or social participation

Secondary Improved walking and outcomes 


\begin{tabular}{|c|c|c|c|c|c|}
\hline $\begin{array}{l}\text { Shevil and } \\
\text { Finlayson (2009) }\end{array}$ & $\begin{array}{l}\text { Process evaluation } \\
\text { (qualitative) }\end{array}$ & 35 people with MS & Self-management (group) & Identify feasibility & $\begin{array}{l}\text { Positive feedback } \\
\text { related to group and } \\
\text { course content }\end{array}$ \\
\hline $\begin{array}{l}\text { Shevil and } \\
\text { Finlayson (2010) }\end{array}$ & Repeated measures & 35 people with MS & Self-management & Pilot findings & $\begin{array}{l}\text { Improved knowledge, } \\
\text { strategy effectiveness } \\
\text { and self-efficacy }\end{array}$ \\
\hline $\begin{array}{l}\text { Smith, Hale, } \\
\text { Mulligan, and } \\
\text { Treharne (2013) }\end{array}$ & $\begin{array}{l}\text { Qualitative } \\
\text { secondary analysis } \\
\text { (see Mulligan et al. } \\
\text { 2013) }\end{array}$ & 27 people with MS & $\begin{array}{l}\text { Combined self-help and } \\
\text { professional help "Blue } \\
\text { Prescription" }\end{array}$ & $\begin{array}{l}\text { Investigate } \\
\text { experience } \\
\text { of participants }\end{array}$ & $\begin{array}{l}\text { Therapy seen as } \\
\text { supportive, motivating } \\
\text { and enabling }\end{array}$ \\
\hline $\begin{array}{l}\text { Stuifbergen, } \\
\text { Becker, Blozis, } \\
\text { Timmerman, and } \\
\text { Kullberg (2003) }\end{array}$ & RCT & 57 people with MS & Self-management (group) & Determine efficacy & $\begin{array}{l}\text { Improved self- } \\
\text { efficacy and health } \\
\text { behaviour at 8MFU. } \\
\text { Immediate } \\
\text { improvement in QOL }\end{array}$ \\
\hline $\begin{array}{l}\text { Stuifbergen, } \\
\text { Becker, } \\
\text { Timmerman, and } \\
\text { Kullberg (2003) }\end{array}$ & $\begin{array}{l}\text { Additional analysis } \\
\text { of RCT }\end{array}$ & 57 people with MS & Self-management (group) & $\begin{array}{l}\text { Describe } \\
\text { experience with } \\
\text { goal attainment } \\
\text { scaling }\end{array}$ & $\begin{array}{l}\text { Increased goal } \\
\text { attainment }\end{array}$ \\
\hline $\begin{array}{l}\text { Twomey and } \\
\text { Robinson (2010) }\end{array}$ & Qualitative analysis & 8 people with MS & $\begin{array}{l}\text { Fatigue management } \\
\text { programme }\end{array}$ & $\begin{array}{l}\text { Examine the } \\
\text { experience of } \\
\text { participants }\end{array}$ & $\begin{array}{l}\text { Experience described } \\
\text { in positive terms }\end{array}$ \\
\hline
\end{tabular}




\section{(d) Support for carers}

\begin{tabular}{|c|c|c|c|c|c|}
\hline Authors \& Date & Design & Sample & Intervention & Aims & Key findings \\
\hline $\begin{array}{l}\text { Diehl, Mayer, } \\
\text { Förstl, and Kurz } \\
\text { (2003) }\end{array}$ & $\begin{array}{l}\text { Single group post- } \\
\text { intervention qualitative } \\
\text { interview }+6 \text { month } \\
\text { questionnaire follow-up }\end{array}$ & 8 carers (FTD) & $\begin{array}{l}\text { Caregiver support } \\
\text { group }\end{array}$ & $\begin{array}{l}\text { (1) To provide } \\
\text { information, advice, } \\
\text { and support to } \\
\text { caregivers, (2) to } \\
\text { establish needs of } \\
\text { caregivers, (3) to } \\
\text { encourage mutual } \\
\text { support and develop } \\
\text { coping strategies, (4) to } \\
\text { evaluate the } \\
\text { intervention }\end{array}$ & $\begin{array}{l}\text { Reduced caregiver } \\
\text { burden, enhanced } \\
\text { coping strategies, } \\
\text { establish new friends, } \\
\text { rated programme as } \\
\text { beneficial }\end{array}$ \\
\hline $\begin{array}{l}\text { Dowling et al. } \\
\text { (2014) }\end{array}$ & $\begin{array}{l}\text { Randomised control } \\
\text { pilot study }\end{array}$ & 24 carers (FTD) & $\begin{array}{l}\text { One-on-one caregiver } \\
\text { positive emotion skill- } \\
\text { building intervention }\end{array}$ & Assess feasibility & $\begin{array}{l}\text { Improved scores on } \\
\text { measures of positive } \\
\text { affect, negative } \\
\text { affect, burden, and } \\
\text { stress for intervention } \\
\text { group. }\end{array}$ \\
\hline $\begin{array}{l}\text { McKinnon, } \\
\text { O'Connor, Savage, } \\
\text { Hodges, and } \\
\text { Mioshi (2013) }\end{array}$ & Between groups & 21 carers (FTD) & $\begin{array}{l}\text { Caregiver support } \\
\text { group }\end{array}$ & $\begin{array}{l}\text { Qualitative evaluation } \\
\text { of intervention }\end{array}$ & $\begin{array}{l}\text { Increased functional } \\
\text { responses to fictitious } \\
\text { scenario }\end{array}$ \\
\hline Mioshi et al. (2013) & Between groups & 21 carers (FTD) & $\begin{array}{l}\text { Caregiver support } \\
\text { group }\end{array}$ & $\begin{array}{l}\text { Verify utility of the } \\
\text { intervention }\end{array}$ & $\begin{array}{l}\text { Burden and reaction } \\
\text { to behaviours } \\
\text { reduced. No change } \\
\text { in depression, stress } \\
\text { and anxiety }\end{array}$ \\
\hline
\end{tabular}


O'Connell et al. Post group feedback

(2014)

Dipple and Evans

(1998)

Shah et al. (2015) Single group pre- and post- intervention

questionnaires and post-

interview
Caregiver support

group

(atypical earlyonset dementia

including FTD)

27 (mix of HD

carers and

people with HD)

7 carers (PD)

\section{Caregiver tele-support} group
Develop and evaluate a support group for rural spouses of individuals with dementia

Describe the support network associated with the group

Assess feasibility
Positive feedback

Infrequent contact outside group meetings

No significant

findings, but scores on Geriatric

Depression Scale decreased from 4.2 to 
Key: CONDITIONS: FTD = frontotemporal dementia, $\mathrm{SD}=$ semantic dementia, HD = Huntington's disease, $\mathrm{PD}=$ Parkinson's disease, $\mathrm{MND}=$ motor neurone disease, $\mathrm{MS}=$ multiple sclerosis, $\mathrm{PPA}=$ primary progressive aphasia, $\mathrm{LBD}=$ dementia with Lewy bodies, $\mathrm{PDD}=\mathrm{Parkinson}$ 's disease dementia, $\mathrm{AD}=$ Alzheimer's disease, $\mathrm{MSA}=$ multiple system atrophy, MS-RR = multiple sclerosis remitting relapsing subtype .

DESIGN: RCT = randomised controlled trial. INTERVENTION: CBT = cognitive behavioural therapy. 

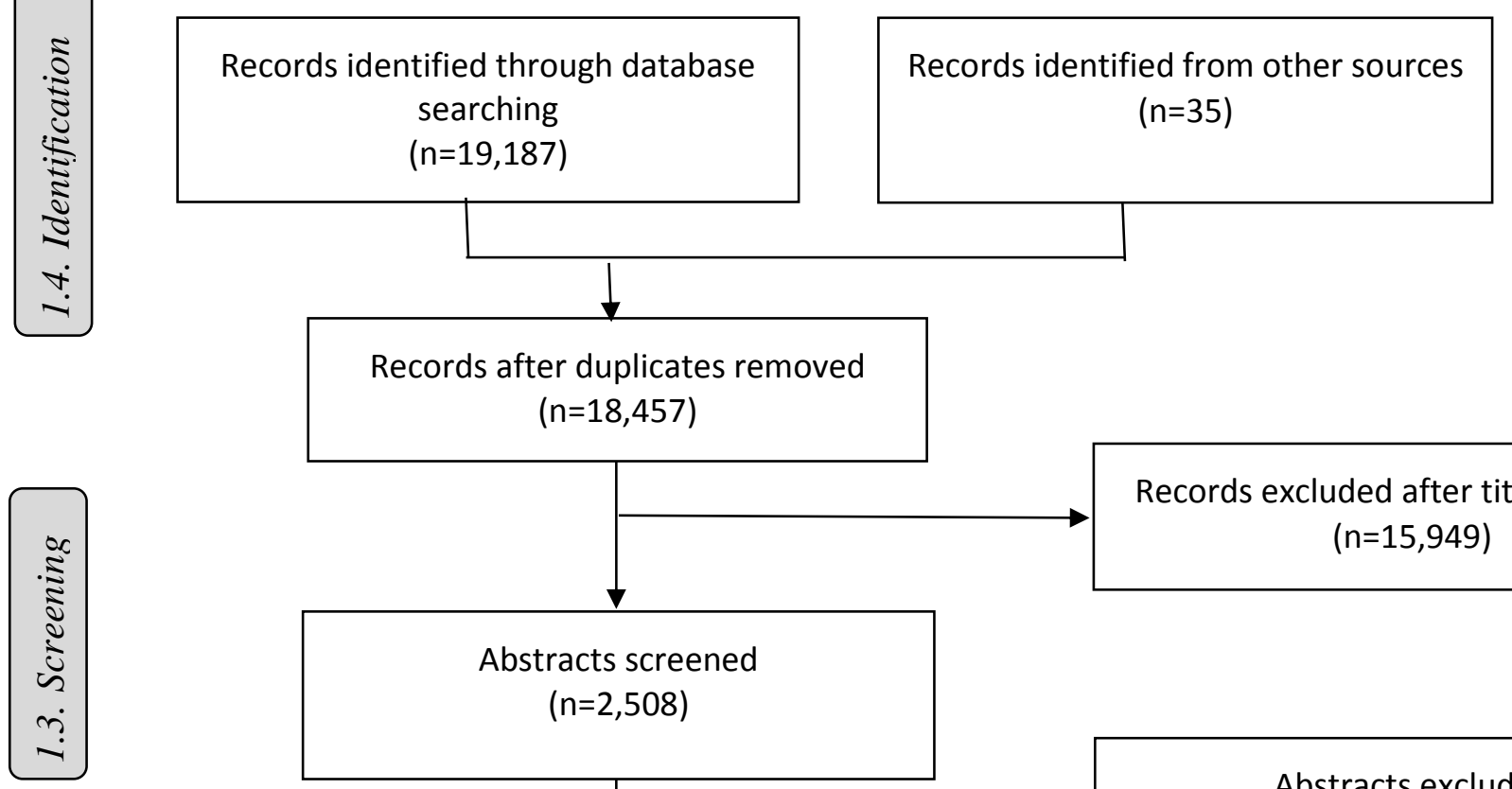

$$
(n=18,457)
$$

Records excluded after title screening ( $n=15,949)$

Abstracts excluded

$(n=1,776)$

Not about condition of interest $(n=96)$

Not about relevant interventions

$(n=1,680)$

Full-text articles assessed for eligibility $(n=732)$

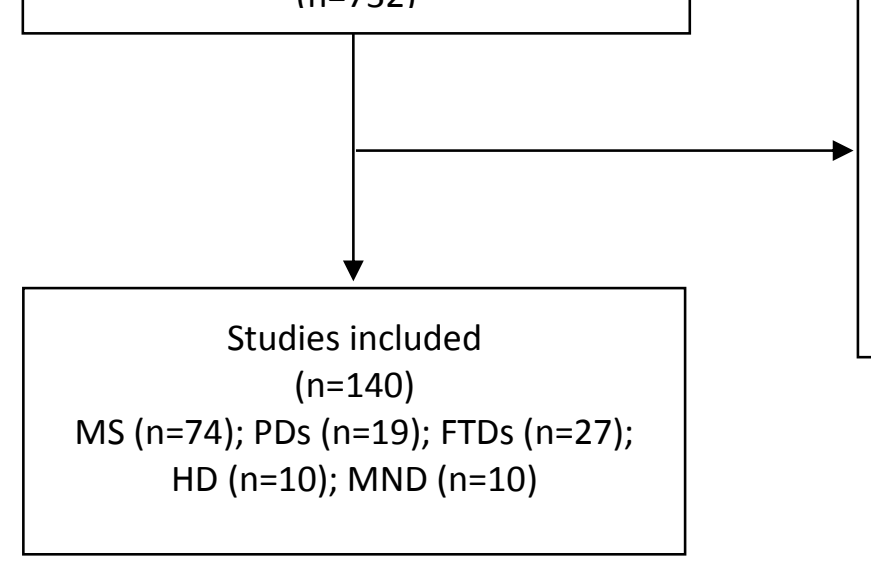

Full-text articles excluded $(n=92)$

Not about condition of interest $(n=41)$

Intervention not relevant or cognitively-impaired participants excluded $(n=397)$

Article unobtainable $(n=154)$

Figure 1. Flow chart illustrating the process of study selection 